\title{
EL CONVENTO DE CORPUS CHRISTI DE MEXICO
}

\author{
Institución para Indias Caciques
}

\author{
POB
}

\section{JOSEFINA MURIEL DE LA TORRE}

FNTRE las acciones del hombre, hay unas que pasan a la Historia como muestras de la animalidad humana ; tales son, por ejemplo, los asesinatos, los saqueos, los incendios, los períodos anárquicos, tiránicos, etc. Pero al lado de estas acciones hay otras que producen obras que nos hacen sentir el orgullo de ser hombres. Estas obras, que nos enorgullecen total $y$ plenamente, son las que edificó el amor. Mas no el amor desordenado, porque el desorden sólo es capaz del crimen. Las obras dignas del hombre las ha hecho el corazón humano, sometido a la disciplina del orden el cual no puede existir, racionalmente, si antes la inteligencia no ha descubierto la jerarquia de los valores. 
El asunto que nos ocupa entra de lleno dentro de este grupo de obras que nacieron de un amor legitimo, porque se sometió al orden pedido por la valoración.

La importancia del convento de Corpus Christi de México, no reside en que haya sido una de tantas casas de la Provincia Franciscana del Santo Evangelio, sino en que es el primer convento para indias caciques qute se funda en América.

Comenzaremos por estudiar, para comprender la importancia de este monasterio, cuáles son sus antecedentes indígenas y españoles.

Empezaremos por considerar la disposición espiritual de las indigenas antes de la Conquista.

Fray Jerónimo de Mendieta, en el Capítulo XVIII de su "Historia Ėclesiástica Indiana", nos dice, refiriéndose a las costumbres de las hijas de los señores principales, que llevaban una vida en extremo austera, y que por costumbre eran laboriosas, honestas y discretas, y tenían especial cuidado en mortificar los sentidos. Añade que las que vivían en los templos indios ayunaban y hacían múltiples sacrificios personales.

Sin hacer comentario alguno dejemos que las páginas de Fray Bernardino de Sahagún nos hablen de ese refinamiento espiritual que los caciques daban a sus hijas.

El capítulo XVIII del Libro Sexto del Tomo Segundo de la "Historia General de las cosas de Nueva España", lleva este titulo que es toda una revelación: "DEL I.ENGUAJE Y AFECTOS QUE LOS SENTORES USABAN HABLANDO Y DOCTRINANDO A SUS HIJAS CUANDO HABIAN LLEGADO A LOS ANOS DE DISCRECION : Exhortábanlas a toda disciplina y honestidad interior y exterior y a la considera. ción de su nobleza, para que ninguna cosa hagan por donde afrente a su linaje, háblanias con muy tiernas palabras y en cosas muy particulares".

Mas por si no bastasen las palabras del maestro Sahagún, entresacamos del capítulo mencionado las que los propios indios dirigían a sus hijas: "Tú, hija mía, preciosa como cuento de oro y como pluma tica, salida de mis entrañas, a quien yo engendré y que eres mi sangre y mi imagen, que estás aquí presente, oye con atención lo que te quiero decir porque ya tienes edad de discreción: Dios criador te ha dado uso de razón y de habilidad para entender, el cual está en todo lugar y es criador de todo". "Nuestro Señor nos dió la risa y el sueño y el comer y el beber con que nos criamos y vivimos y diónos también el oficio de la generación, con que nos 
multiplicamos en el mundo; todas estas cosas dan contento a nuestra vida por poco espacio". En seguida habla del dolor que hay en el mundo comparándolo con el poco placer que en él existe, y añade: "esto que está dicho es muy gran verdad, que pasa así en el mundo, mas nadie lo considera, nadie piensa en la muerte; solamente se considera lo presente que es el ganar de comer y beber y buscar la vida, edificar casas y trabajar para vivir y buscar mujeres para casarse..." "Es menester que sepas cómo has de vivir y cómo has de andar tu camino, porque el camino de este mundo es muy dificultoso, y mira hija mía, palomita mia, que el cannino de este mundo no es poco dificultoso sino es espantablemente dificultoso". "Sábete que eres noble y generosa, considérate y conócete como tal; aunque eres doncellita, eres preciosa como un chalchihuite y como un zafiro y fuiste labrada y esculpida de noble sangre y generosos parientes". "Y esto que te digo hija mia, bien lo entiendes". "Mira que no te avergüences a tí misma, mira que no avergüences y afrentes a nuestros antepasados señores y senadores; mira que no hagas alguna vileza, mira que no te hagas persona vil pues eres noble y generosa".

En el mismo capitulo nos informa también de esa vida de austeridad que ya mencionamos en la obra de Fray Jerónimo de Mendieta.

En el Tomo III, Capitulo XIII del Libro X, de la obra de Sahagún encontramos descrito lo que era para los nahoas una mujer noble. "La mujer noble es muy estimada, digna de honra y reverencia, y por su virtud y nobleza en todo da favor y amparo a los que acuden a ella; y la tal si es buena, tiene estas propiedades, que debajo de stis alas se amparan los pobres, y los ama y los trata muy bien, amparándolos; y si no es tal es apasionada, de malas entrañas, no tiene en nada a los otros por ser soberbia y presuntuosa".

De todos estos preciosos párrafos podemos sacar las siguientes con. clusiones :

I.-Que la teogonia indígena reconoce valores supremos, a los cuales subordina la vida, y entonces el amor se ordena sometiendo a las acciones a una rigurosa disciplina.

II.-Que el sentido de la aristocracia indigena es bastante perfecto, pues la nobleza se encuentra obligada a poseer todas las virtudes. Se siente la responsabilidad que trae consigo una elevada posición.

No he tratado de probar con esto que todas las indias principales fuesen buenas, sino únicamente de demostrat que existían en el elemento 
indio las cualidades necesarias no sólo para la comprensión del cristianismo, sino para vivir en él las austeridades de la vida religiosa.

Con la aparición del catolicismo surge para las indias un grave problema. Se acostumbraba en la época precortesiana que las hijas de los nobles entrasen, en cuanto llegaban a la edad de discreción, en el templo llamado Calmecac, lugar en donde se les enseñaba a orar y a llevar una vida digna de su nobleza y de donde salían sólo las que iban a casarse.

Las palabras del padre que entrega a su hija a las maestras del Calmecac, en las cuales le dice que alli no va ser servida, ni obedecida, sino humillada $\mathrm{y}$ abatida, recomendándole además que castigue su cuerpo y no se acuerde de nada carnal, nos pone de manifiesto la importancia que en la vida indigena tenían esas clases de recogimiento.

Pero ya las naves del gran almirante han engrandecido el reino de Fernando e Isabel. Ya don Hernando ha realizado su grandiosa conquista. $\mathrm{Ha}$ llegado España! La España del siglo XVI que lanza para la conquista espiritual de los pueblos a los soldados que usan por armas la Cruz, que hechizan al indio con su canto y lo vencen con el amor. Han llegado los Franciscos, los hijos de Domingo de Guzmán, los Agustinos, y, al contacto de la Cruz, el canto y el amor, ha nacido la Nueva España. La nación tiene ya catedrales, palacios, conventos; hay grandes colegios y hasta Universidad. Ya no existe el templo indio; ya las jóvenes nobles no van al Calmecac. Algunos conventos de monjas como el de las Concepcionistas, educaban a las niñas pero sólo por un breve tiempo, porque después de recibir los conocimientos elementales para una mujer, debian irse a sus casas. Se les había predicado el cristianismo, se les habian señalado los peligros del mundo y las perfecciones de la vida religiosa, pero ésta no se les permitía adoptarla.

Existía pues, un estado de injusticia; ellas eran cristianas, la Iglesia las reconocía como tales $y$, sin embargo, no se les permitía vivir en el estado que la Iglesia consideraba más perfecto. Esto se debía a la idea de que las indias no sabrian comprender la significación de dicho estado. Algunos motivos justificaban tal creencia, pues la masa indígena conservaba muchos restos de paganismo, y, a pesar de su cristianismo, eran sumamente ignorantes en materia religiosa. Pero si esto pasaba con la mayoría, había un gripo selecto que entendía perfectamente lo que era la vida monástica, que comprendía bien la reli- 
gión y la sabia vivir, al grado de llamar la atención de la sociedad colonial por sus virtudes.

Este grupo estaba constituido por la nobleza y no habia ningún derecho para negar a sus miembros el ingreso a los conventos. Las indias nobles que no tenían medios para ingresar a los monasterios como religiosas, entraban a ellos como criadas de las monjas españolas, to cual, como es de adivinar, les traía grandes penas. Los caciques veían con tristeza que sus hijas no tenían ya lugares para vivir en la forma que su corazón les pedia.

Habian transcurrido varios siglos desde la desaparición del Calmecac en esta situación injusta que impedia a las indias realizar su vida con la perfección espiritual que legitimamente anhelaban. Ėl año de 1720 el Virrey don Baltazar de Zúñiga, Marqués de Valero, concibe la idea de fundar un convento exclusivamente para indias hijas de caciques.

\section{ORIGEN Y MARCO HISTÓRICO}

El Marqués sabe mejor que nadie el complicado manejo de esa maquinaria que era el Gobierno Español; así empieza su obra con una carta al Rey Felipe V en que le expone sus deseos, ya que por causas del Real Patronato sólo el Rey podía autorizar la fundación. El Rey ordena la investigación.

El Consejo de Indias, la Real Audiencia, el Clero y el Virrey empiezan a moverse. Mientras se hace la investigación; el Virrey, con una plena confianza en el monarca, y dando una prueba de su gran interés, ordena la construcción del convento.

Por otra parte, las monjas que el Virrey ha escogido para la fundación, se dirigen a Su Santidad Benedicto XIII, pidiéndole que conceda para el Convento de Corpus Christi de México, que va a fundarse, la regla más austera. Piden vivir en perpetuo aytuno y abstinencia, y no alimentarse más que con los cereales más pobres como eran el maíz, el haba y el frijol.

Es bien sabido que en los grandes conventos de México las monjas vivian regaladamente y eran servidas como en sus casas por multitud de criadas; pues bien, nuestras monjas piden a Su Santidad que la clausura sea tan estricta, que no se permita violarla "a mujer alguna del siglo ni de cuatro años". 
Ëntretanto, la investigación que el Rey pedía se había hecho. Las autoridades civiles habían resuelto en favor del Marqués de Valero, las religiosas, en cambio, se hallaban indecisas ante la oposición de los padres de la Compañía de Jesús.

En el Archivo General de la Nación, existen las cartas de este proceso $\mathrm{y}$ en elias se lee que la oposición se fundaba en que, según el decir de los padres de la Compañía, las indias, por su poca capacidad mental no comprendian el estado religioso, pues existiendo ya dos conventos para indias, uno en Querétaro (Santa Clara), fundado por un cacique, y otro en México denominado "De la Limpia y Pura Concepción", la ausencia de indias en ellos estaba demostrado que no podian vivir en la rigide $z$ de la vida monástica.

El tribunal ordena que se investigue en los dichos conventos. Las prueBas se presentan y son favorables al Virrey, pues queda demostrado que en los dichos conventos nunca se admitió a indias. Por otra parte, los diversos conventos de monjas que habian educado a multitud de niñas indias y los curas de las distintas parroquias informan en bellísimos párrafos acerca de las virtudes y aptitudes religiosas de las indias nobles.

Terminada la investigación, se envia el resultado a España, pero entretanto, han sucedido grandes cambios políticos. El Rey Felipe $\mathrm{V}$ abdica la corona y se retira al Monasterio de San Ildefonso, dejando en el trono al joven Infante Don Luis.

Hay un nuevo rey, pero ¿qué importa a la obra del Virrey de México, cuando ya es tradición que los gobiernos continúen las obras de sus predecesores?

Luis I es quien recibe la información pedida por su padre y la contesta analizando los informes con la minuciosidad de un Felipe II; después, declarándose partidario del Marqués de Valero, defiende a las indias diciendo que: "son tan proporcionadas al estado religioso, que casi por inclinación lo profesan en el siglo" y concluye con el mandato: "He resuelto sobre la consulta del referido mi consejo del 21 de febrero próximo pasado conceder (como por la presente concedo) al Marqués de Valero, licencia y facultad para que funde un convento de religiosas Franciscas descalzas, en la Ciudad de México, para indias principales y hijas de caciques que se inclinaren al estado religioso y quisieren profesarse en él, en calidad de que esta fundación se haga y efectúe en todo lo prevenido y dispuesto por las Reglas de mi Real patronato". 
Por último el Rey ordena a las autoridades civiles y pide humildemente a las eclesiásticas que se funde dicho convento con las mismas reglas que las Descalzas Reales de Madrid,

E.l Papa Benedicto XIII en el Breve del 26 de junio de 1727 aprueba la fundación rectificando que el convento de Corpus Christi de México se reservará únicamente para indias nobles.

Las aprobaciones llegan; la obra material de la fábrica del convento ha sido concluida.

Se escogen de entre las monjas de algunos conventos a aquellas españolas que reúnen las mejores condiciones de idoneidad para realizar la fundación.

Se tiene gran cuidado en la selección, pues no era cosa fácil de convivir con las indias en calidad de iguales, cuando había sido costumbre (como la era en los monasterios) tratarlas como criadas. Además las indias tenían una instrucción muy escasa, sólo una que otra de ellas habia sido instruida en los conventos de monjas ("La Concepción" de México, "Los Gozos" de Puebla, etc.) o con las maestras particulares que existian. $\mathrm{Y}$ inabía algo más grave aún: la diferencia de carácter. El español es duro, aún hoy hablamos con un español $y$, a pesar de su hidalguía, su lenguaje es para nosotros poco amable. El indio es más dulce; creo que por los párrafos leídos de la obra de Sahagún tođos lo habrán comprendido.

Por todos estos motivos fueron escogidas cuatro religiosas: Sor Gregoria Micaela de Jesús Nazareno, del convento de Santa Isabel; Sor Micaela de San José, del de Santa Clara y Sor Teresa de San José y Sor Petra de San Francisco del de San Juan de la Penitencia. La última, que es designada por stuperiora, es criolla, fueron sus padres Sebastiana de Luna y Pedro de Alvarado, descendiente del famoso conquistador del mismo nombre.

Fué a Sor Petra de San Francisco, mujer de noble linaje, instruída e inteligente, como lo demuestran sus escritos, a quien se le entregó el convento de Corpus Christi. Ella fué quien examinó a las indias que pretendían el hábito y quien presentó la lista de pretendientas al Virrey para que éste designase cuáles serian admitidas inmediatamente.

Conciuídos ya los últimos detalles, se inaugara el monasterio el jueves de Corpus de 1724.

No voy a describir las fiestas profanas que hubo con este motivo, pues ya los deliciosos relatos de don Artemio de Valle-Arizpe os habrán informado sobre las verbenas populares de aquellos tiempos; sin embargo, hay 
en ésta un aspecto nuevo, que da el elemento indigena que concurre a la ciudad.

La fiesta religiosa se celebra dentro, asistiendo a ella el Virrey Marqués de Casa Fuerte, sucesor del Marqués de Valero, pues éste había sido trasladado a España donde, en esta época tenía el cargo de Presidente del Real Consejo de Indias, el Arzobispo y demás miembros del Clero, y en especial la Orden Franciscana.

Pero alli están también los Caciques, que vuelven como en siglos anteriores a llevar a sus hijas al templo, pero ya no es el Calmecac indio al cual la tiranía azteca obligabaa a entrar, es el convento cristiano que se abre para quien libremente quiera entrar a él.

Las jóvenes dejan sus joyas, sus trajes, sus cabellos son cortados y sólo reciben por toda vestimenta tres túnicas y un manto de sayal muy burdo, un velo y unas sandalias de cáñamo.

Tres dias duraron las fiestas y después de ellas comenzó la vida conventual.

\section{VIDA DE CONVENTO}

Anécdotas, reglas, fines, condiciones de ingreso.-Los indios frente a esta institución

Respecto a la vida conventual he logrado formar una nómina que abarca desde el año 1741, hasta casi la extinción del convento, en la cual tengo ya anotados los datos de todas las monjas que a partir de ese periodo lo habitaron. Estos datos se refieren a los nombres de las indias, los de sus padres, lugar de donde eran caciques y oficios a los que se dedicaban, y dado el interés que encierra todo lo relativo a la vida de los indios en la época colonial, se publica en el apéndice.

No he podido aún completar la nómina para hacerla nacer desde el año 1724, porque no he encontrado el primer libro de las "Informaciones"; sin embargo, sé que antes del año 1741 , hubo cuarenta y seis religiosas porque el segundo libro de las "Informaciones" empieza con Sor Francisca Tomasa de la Santísima Trinidad, que ocupa el lugar número cuarenta y siete.

Sin embargo, por el libro llamado "Biografías de Algunas Religiosas", obra manuscrita que he tenido en mi poder, por el folleto publicado 


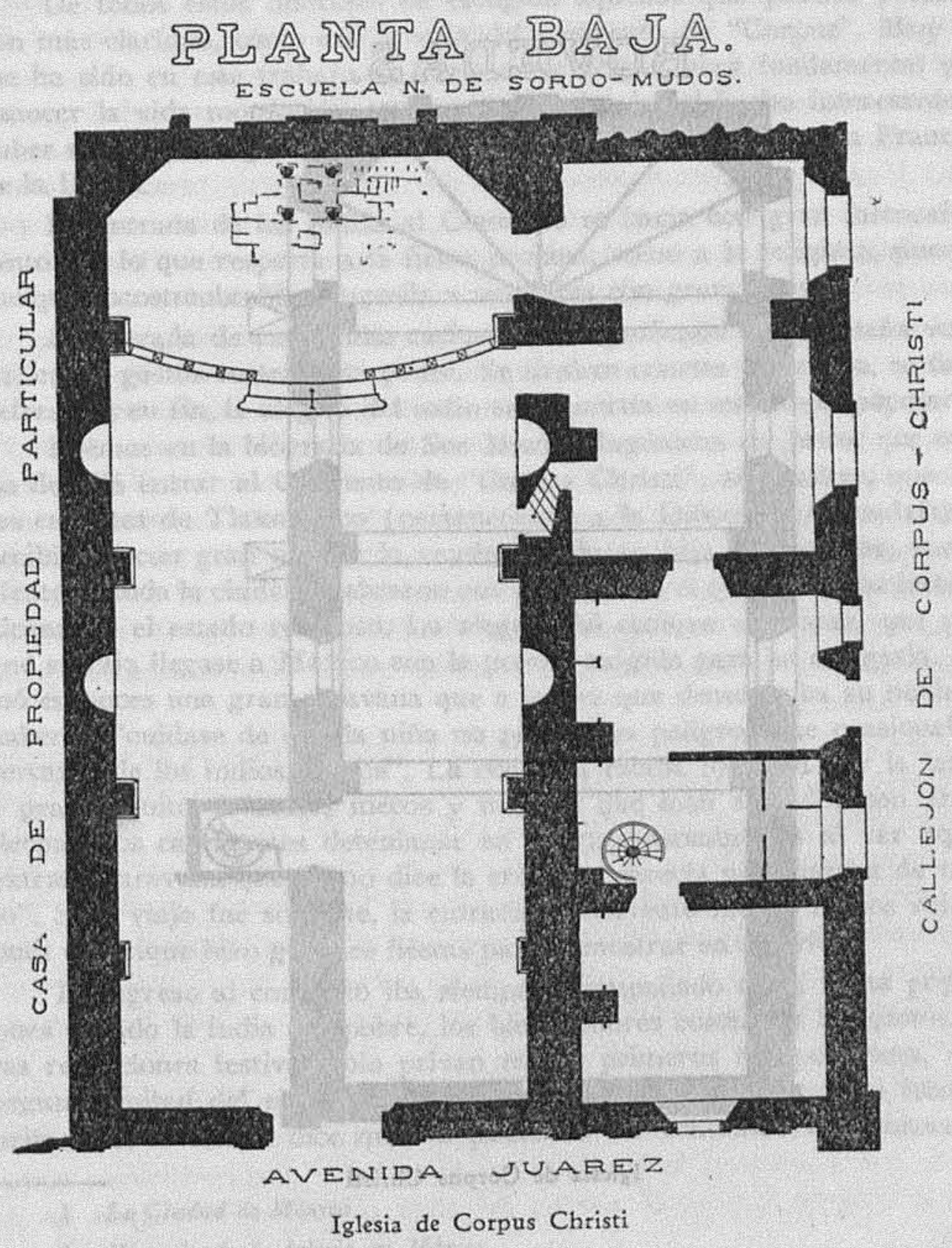


DOI: http://dx.doi.org/10.22201/iie.18703062e.1941.7.227

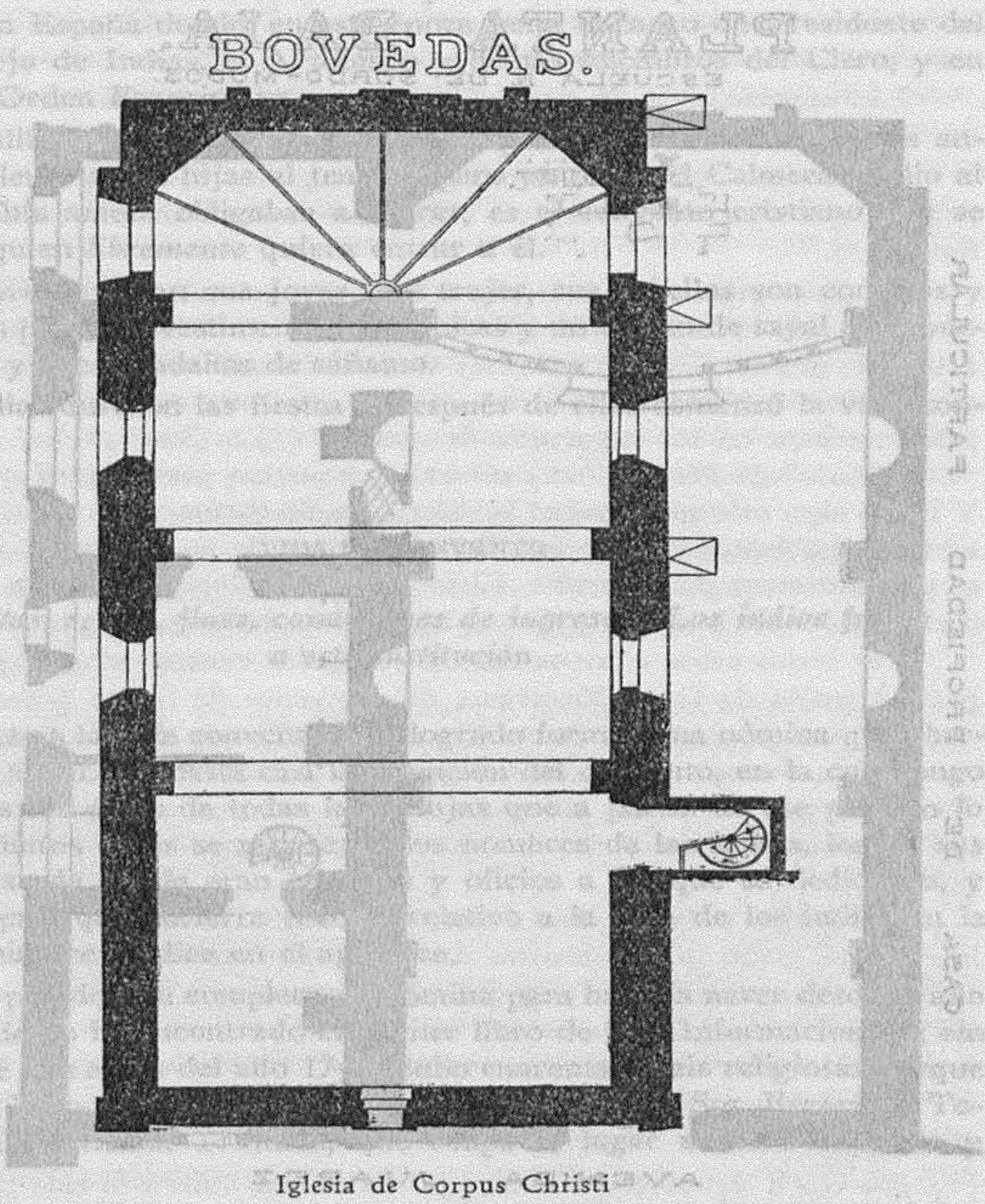


con motivo de la inauguración del Convento, por el libro de las "Patentes", por algunas de Marroqui, 1 y del Padre Cuevas, 2 he logrado conocer algunos preciosos datos acerca de las religiosas que me faltaban.

De todos estos informes he escogido aquellos que pueden presentar con más claridad, cómo era la vida del Convento de "Corpus". Muy útil me ha sido en este trabajo el Libro de la Regla, obra fundamental para conocer la vida monástica, que presenta además, el hecho interesante de haber sido impresa gracias a la magnanimidad de don José y don Francisco de la Borda.

La entrada de las indias al Convento se hacia con gran fastuosidad, tanto por lo que respecta a la fiesta profana, como a la religiosa, pues los caciques acostumbraban despedir a sus hijas con gran pompa.

La entrada de cada india cacique rica significaba una pequeña verbena, cuyos gastos costeaba su padre. Se tiraban cohetes de bomba, se daban refrescos; en fin, la alegría del indio se convertía en una fiesta popular.

Leemos en la biografía de Sor Maria Magdalena de Jesús, que cuando decidió entrar al Convento de "Corpus Christi", sus padres, que eran los caciques de Tlaxomulco (perteneciente a la Diócesis de Guadalajara) recibieron con gran alegría la resolución de su hija y que ellos, sus parientes y toda la ciudad celebraron con gran júbilo el que las indias bubiesen alcanzado el estado religioso. La alegría del cacique era tanta, que quiso que su hija llegase a México con la pompa exigida para su categoría. Formó entonces una gran caravana que a la vez que demostraba su nobleza y haberes, "cuidase de que la niña no pasase los peligros que $\propto$ casionaba la cercanía de los indios bravos". La comitiva estaba formada por la familia y gran séquito de indios mecos y manzos que iban armados con arco y flecha. Los caminantes detenianse en su ruta asombrados al ver aquella extraña caravana que, como dice la crónica "parecía una marcha de triunfo". Si el viaje fué solemne, la entrada al convento fué no menos ruidosa; pues el cacique hizo grandes fiestas para demostrar su alegria.

El ingreso al convento iba siempre acompafiado de la fiesta popular, pues cuando la india era pobre, los bienfiechores costeaban los gastos. Estas recepciones festivas sólo privan en los primeros tiempos, pues, en la segunda mitad del siglo XVIII aparecen diversas brdenes para irlas suprimendo; la última dice que no pudiendo ser contenido el alborozo po-

1 La Ciudad de México.

2 Historia de la Iglesia en México. 
pular, que no respeta la sacristía ni la iglesia, y para impedir los gastos inútiles de obsequios y refrescos que hacen los padres y bienhechores, se prohibe la recepción de novicias con las fiestas acostumbradas, $y$ se ordena que la entrada se haga en forma privada. Asi desaparecen estas alegres recepciones que debieron dar al convento de Corpus Christi de la Ciudad de México un aspecto muy singular.

Respecto a la vida interior del Convento, hay que recordar que se trataba de una orden mendicante que no poseía bienes propios, pues cuando las jóvenes caciques profesaban, tenian que repartir previamente sus bienes entre las personas que deseasen, ya fuesen parientes, amigos pobres o instituciones; esta falta de bienes les permitía vivir libres de la tiranía de los negocios y dedicadas únicamente a la vida contemplativa.

Sin embargo, en las horas de labor que exige la regla, las monjas se ocupaban en bordar ornamentos, frontales, cortinas y otros objetos. Me imagino, fundándome en los documentos, cómo, por la tarde, reunidas en la sala de labor, bordaban con sus manos morenas los símbolos de la liturgia cristiana, y mientras sus manos subian y bajaban, en el monótono entrar y salir de los hilos de oro y plata, la lectora iba cacaneando una lectura piadosa, acaso de Fray Luis de León. Los pájaros, los arroyos de la huerta y las pesadas carretas que venian del Molino del Rey, del de Belem, del de Santo Domingo o del de Valdés, pasaban por el callejón de "Corpus Christi" y ofrecian asi el fondo en que se desarrollaba la apacible vida conventual.

Pero no todo era rezar y coser; había también momentos de recreación y en algunos de ellos las monjas hacian representaciones teatrales. Tal vez eth algún tiempo asistieron a ellas los capellanes del convento; los provinciales franciscanos y hasta la Virreina; así se deduce de una carta del año 1753 en que el Provincial de la Orden Franciscana prohibe "que se represente cosa alguna delante de personas extrañas, aunque éstas sean sacerdotes". Respecto a los originales de las obras que representaban, tengo noticias de que fueron quemadas, cosa lamentable, cuando tuvo lugar la exclaustración.

Otra de las ocupaciones de las religiosas fué el cuidado de la huerta en la cual tenían un jardín dedicado especialmente al cultivo de las flores con que adornaban la iglesia, y cuidaban muy particularmente aquellas que hicieron famoso el adorno del altar el Jueves de Corpus en su templo. 
La vida que se desarrollaba allí con la mayor tranquilidad se vió alterada por los años de 1726 a 1727, pues tres españolas ingresaron al convento, de modo irfegular, y empezaráni a tratar a las indias con toda dureza. Como una de ellas se quejase a los superiores, fué encarcelada por las españolas, y murió en la prisión poco tiempo después. La tradición cuenta, alrededor de su muerte, una leyenda según la cual cierta mañana, al salir las religiosas del coro, escucharon bellos cantos y percibieron aroma de rosas. Los vecinos llegaron al convento a preguntar qué fiesta celebraban con tan hermosa música, prtes que hasta la calle se oía. Las monjas recorrieron entonces el Convento para encontrar de dónde provenia aquello, y dieron con la prisión de Sor Maria Juana del Espíritu Santo, a quien hallaron muerta. Hasta aqui esta tradición verbal.

Informado el Rey de lo ocurrido, escribió una carta al Fiscal de lo Civil de la Ciudad de México en la que, después de considerar que la fundación había sido hecha por el Marqués de Valero sólo para indias caciques, y que en tal forma había sido aprobado por cédula real y por 1a Bula de Benedicto XIII, declara que las españolas están quebrantando la clausura y "causando inquietud y desasosiego espiritual a las indias" por su diversidad de genio y que, por lo tanto, ordena salgan inmediatamente del convento aunque hubiesen ya profesado, y que no se admitan más que a indias principales y caciques.

Después de este decreto ninguna española volvió a pisar el convento.

Veamos ahora quiénes fueron sus ilustres moradoras.

Existiendo la orden de que sólo habitaran indias hijas de caciques, los requisitos de ingreso para hacer que esta condición se cumpliera, fueron múltiples; entre ellos señalaremos algunos.

Una vez que la india habia puesto su pretensión en el Convento, la comunidad nombraba a uno de los frailes menores para que éste comprobara si la india reunía los requisitos.

La investigación se hacía en la siguiente forma: Primero se sacaba copia de la partida de bautismo de la joven; en seguida se reunía a cierto número de habitantes (cuatro o más) del pueblo o barrio a que pertenecía y entonces se les sometía a un interrogatorio por medio del cual se comprobaba: I.-Si era noble o cacique no tributaria por merced real. II.-Si era descendiente de limpio linaje, sin mezcla, es decir, india pura. III.-Si en ella o en sus ascendientes no había habido "alguna infamia vulgar, esclavitud a oficio vil".. IV.-Si no habian sido ella o sus 
DOI: http://dx.doi.org/10.22201/iie.18703062e.1941.7.227

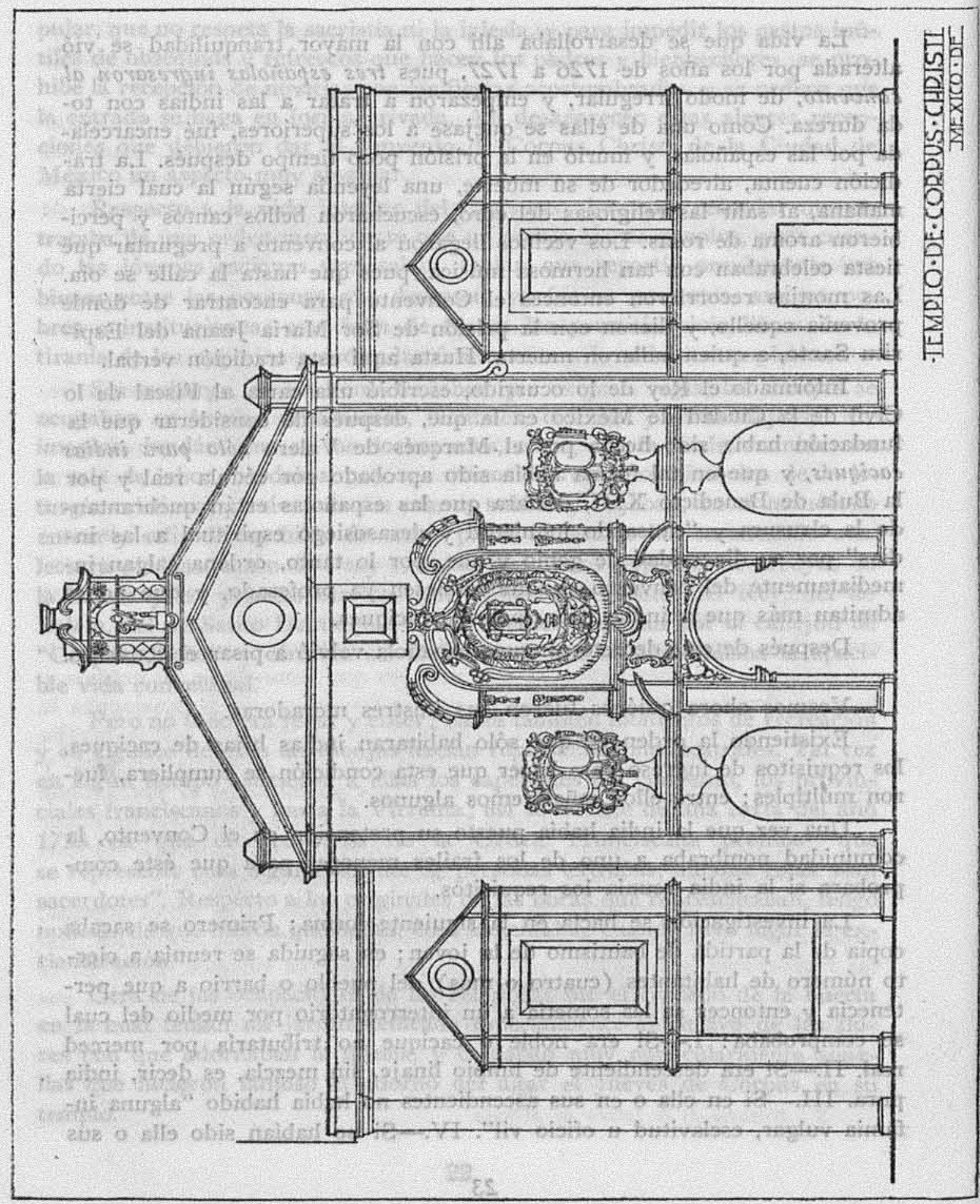




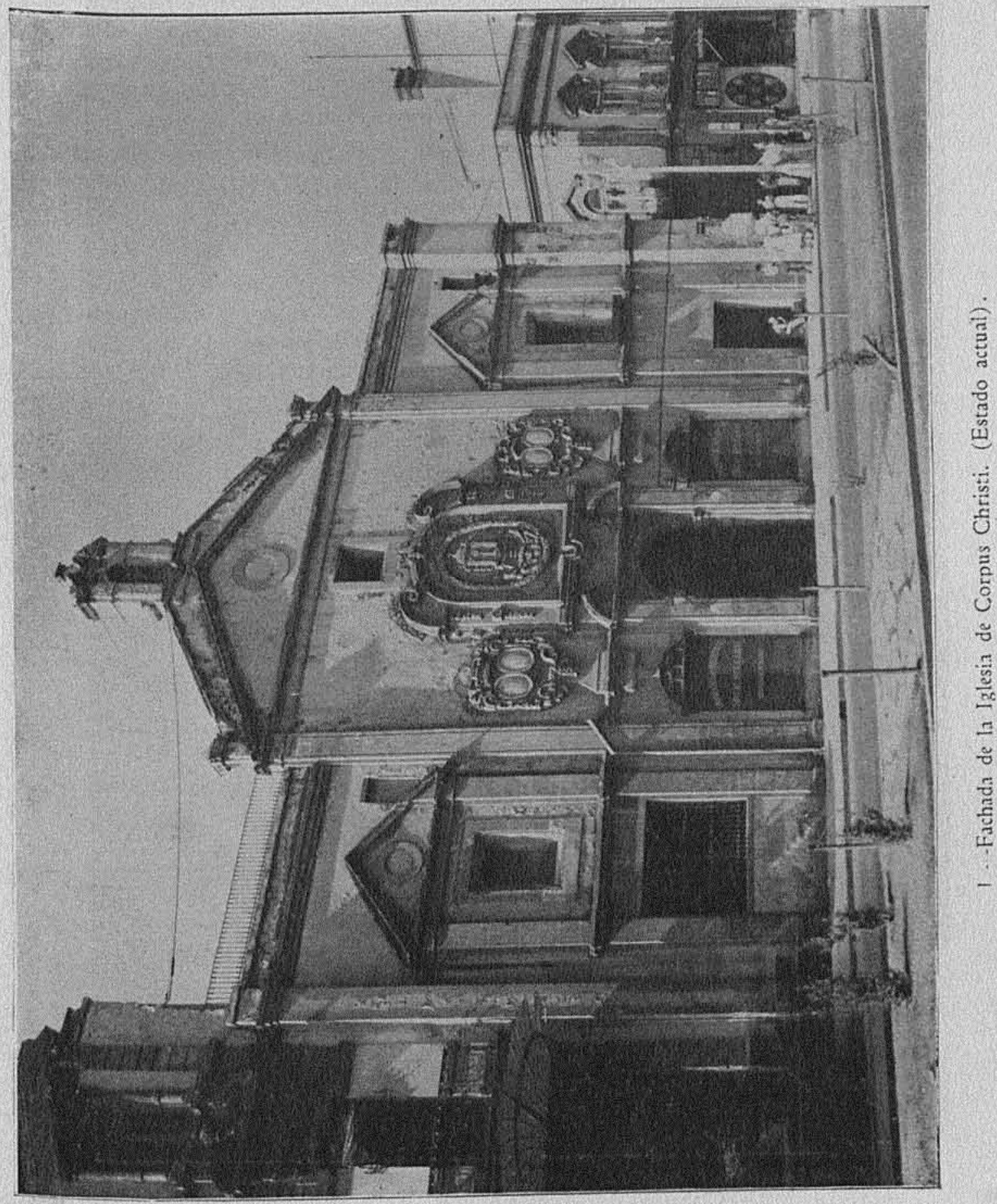




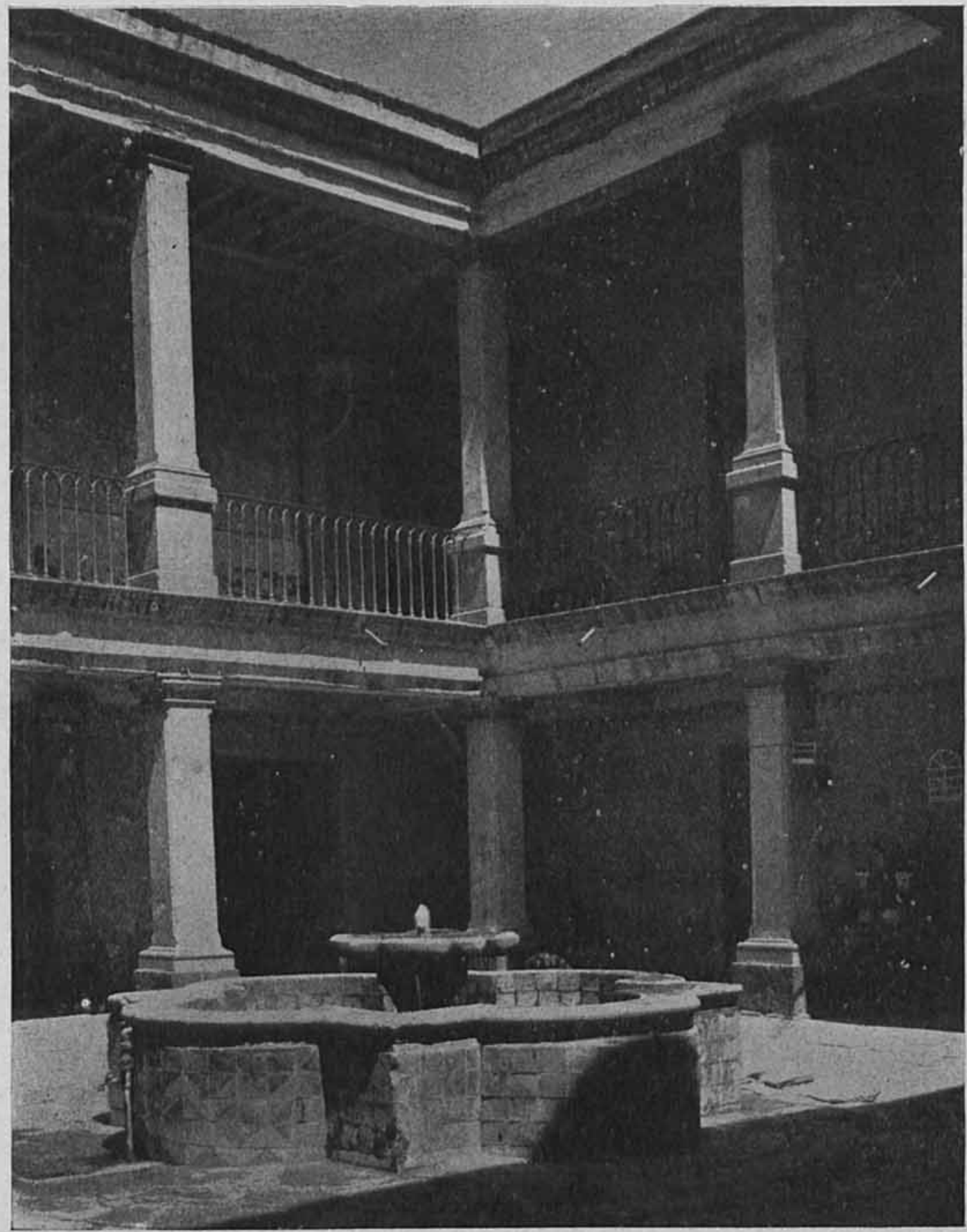

2.-Claustro del convento. (Estado actual). 


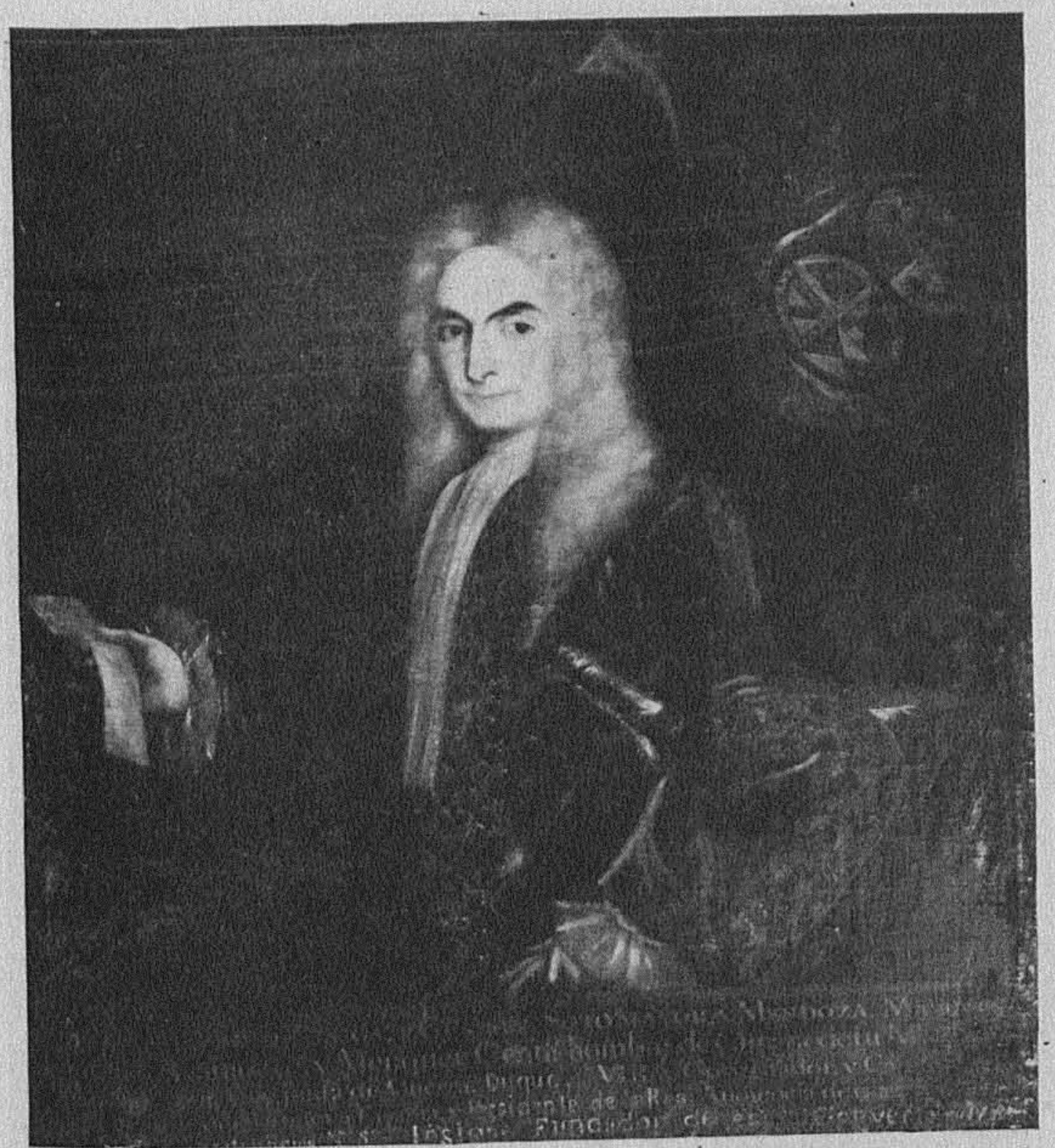

3.-Retrato del Virrey Marqués de Valero. 
DOI: http://dx.doi.org/10.22201/iie.18703062e.1941.7.227

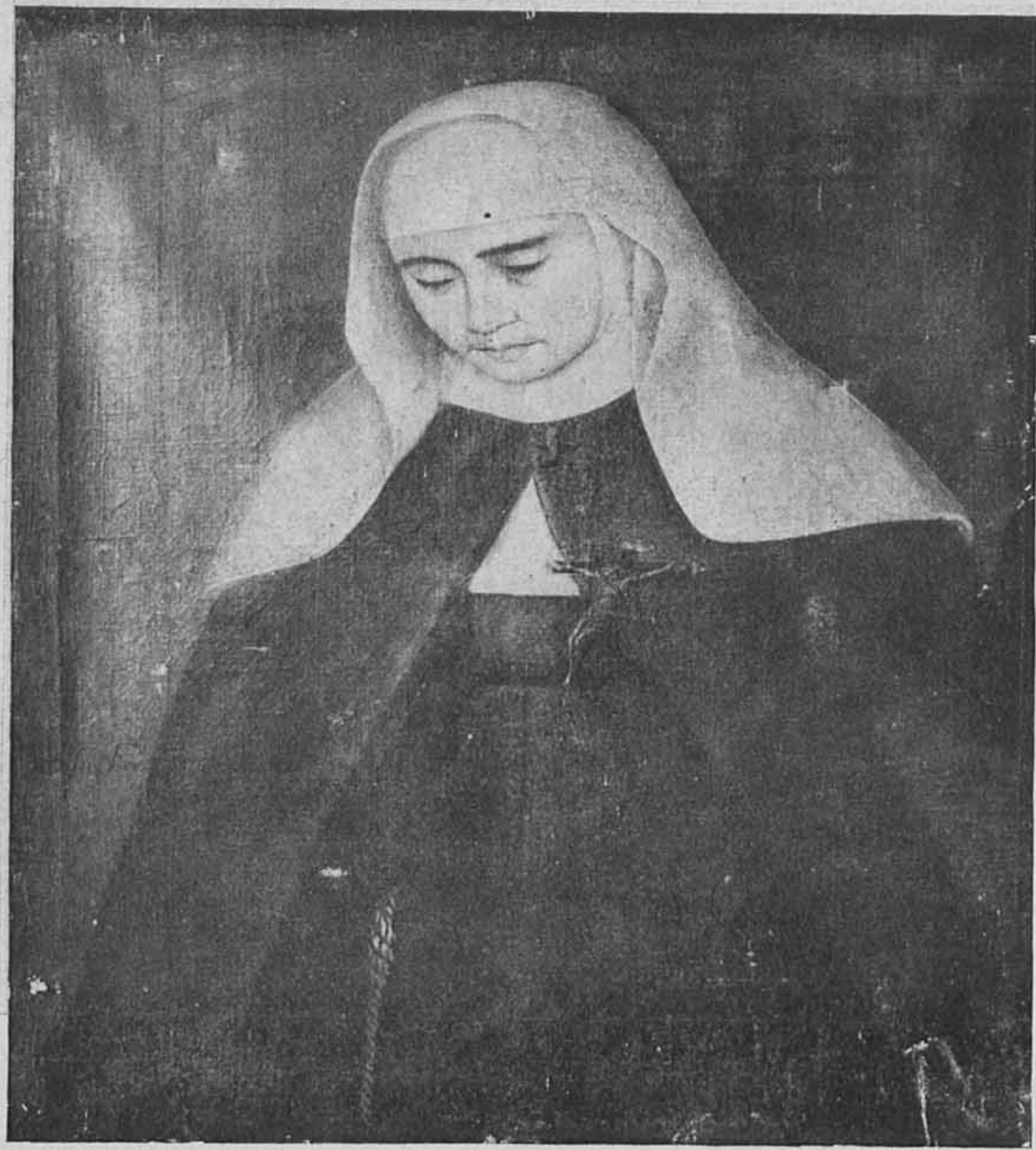

4.-Retrato de una de las Monjas Fundadoras. 

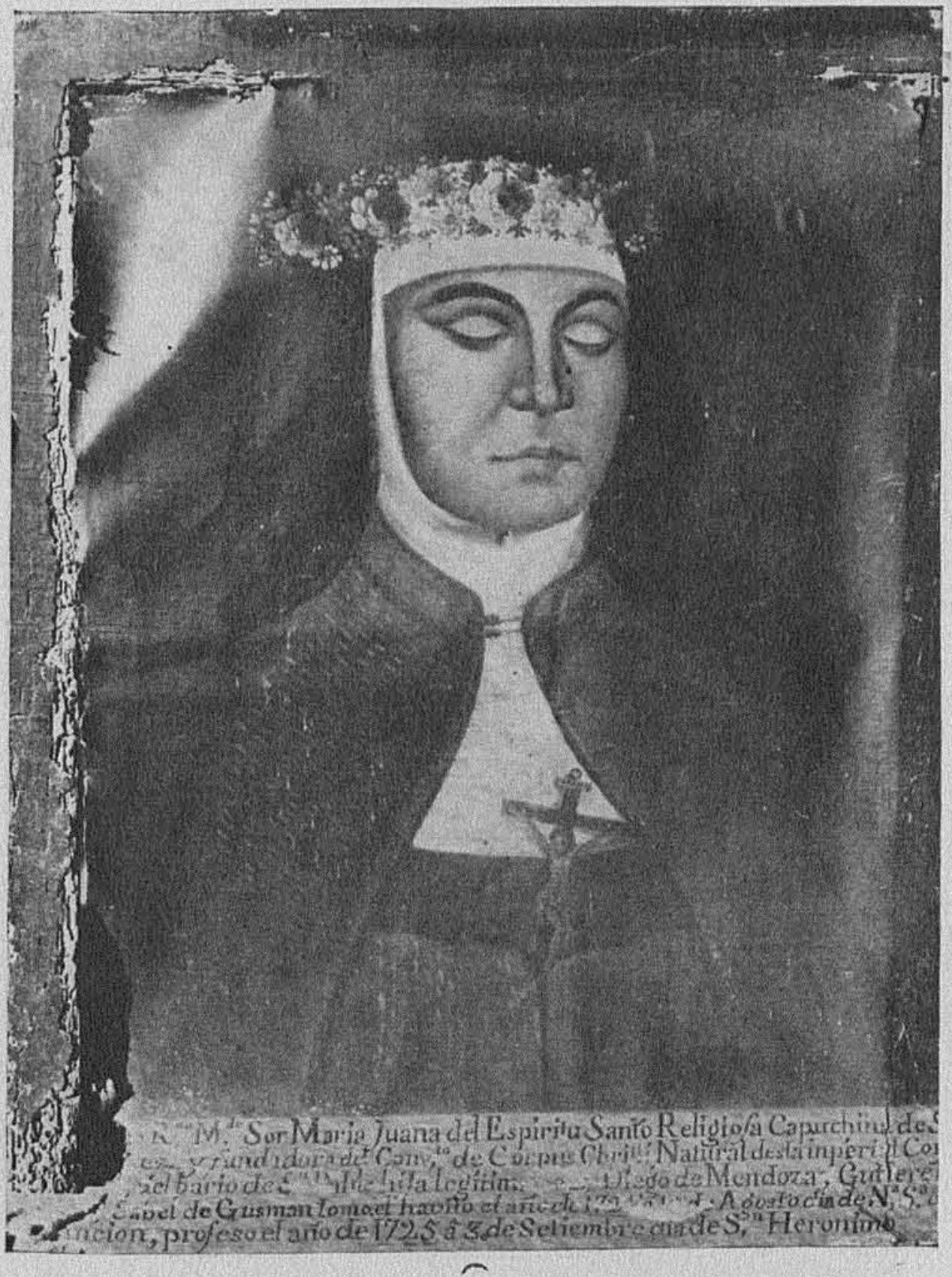

5.-Sor Maria Juana del Espiritu Santo. 
DOI: http://dx.doi.org/10.22201/iie.18703062e.1941.7.227

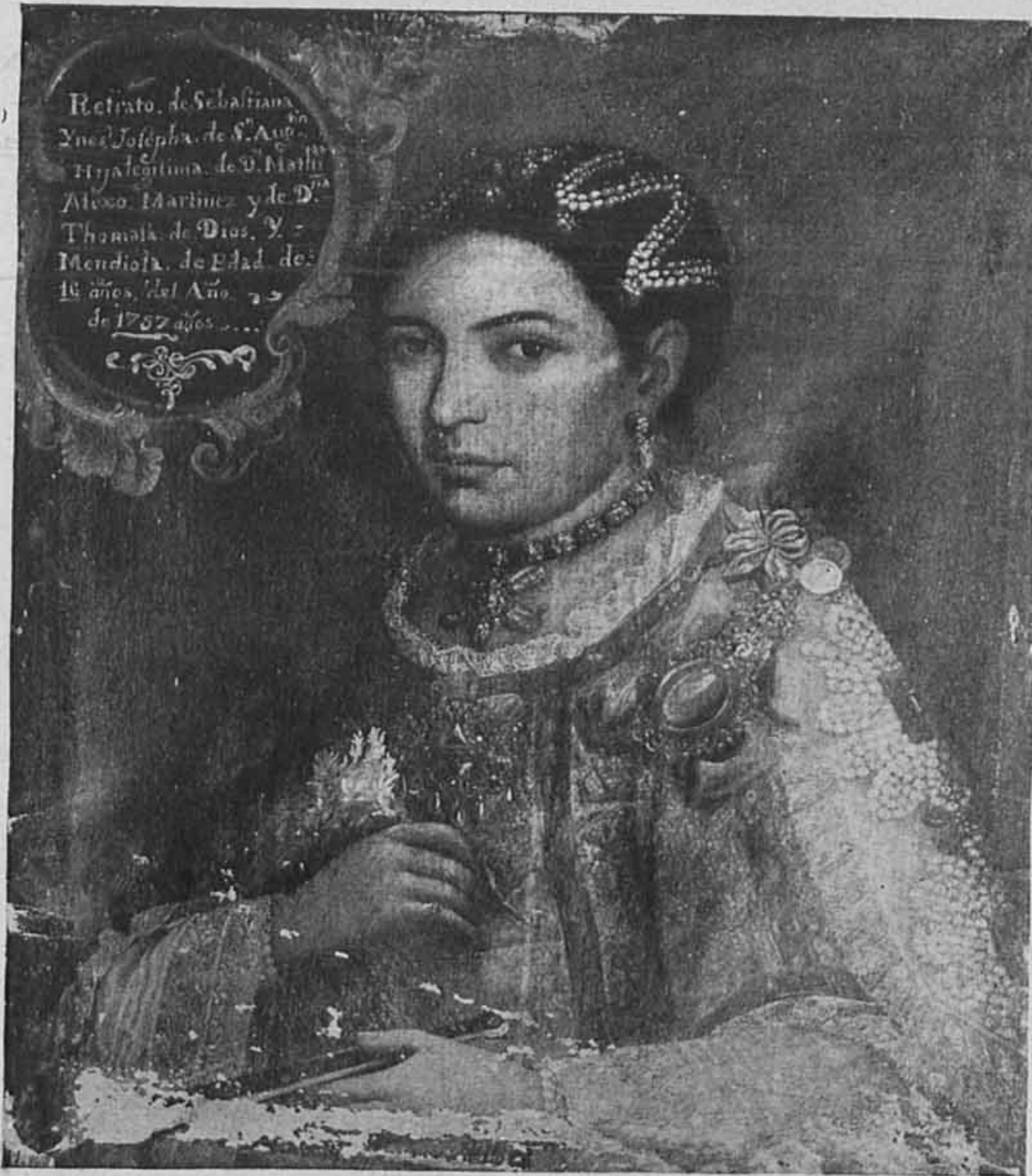

6.- India cacique, ataviada para la toma de velo. 
DOI: http://dx.doi.org/10.22201/iie.18703062e.1941.7.227

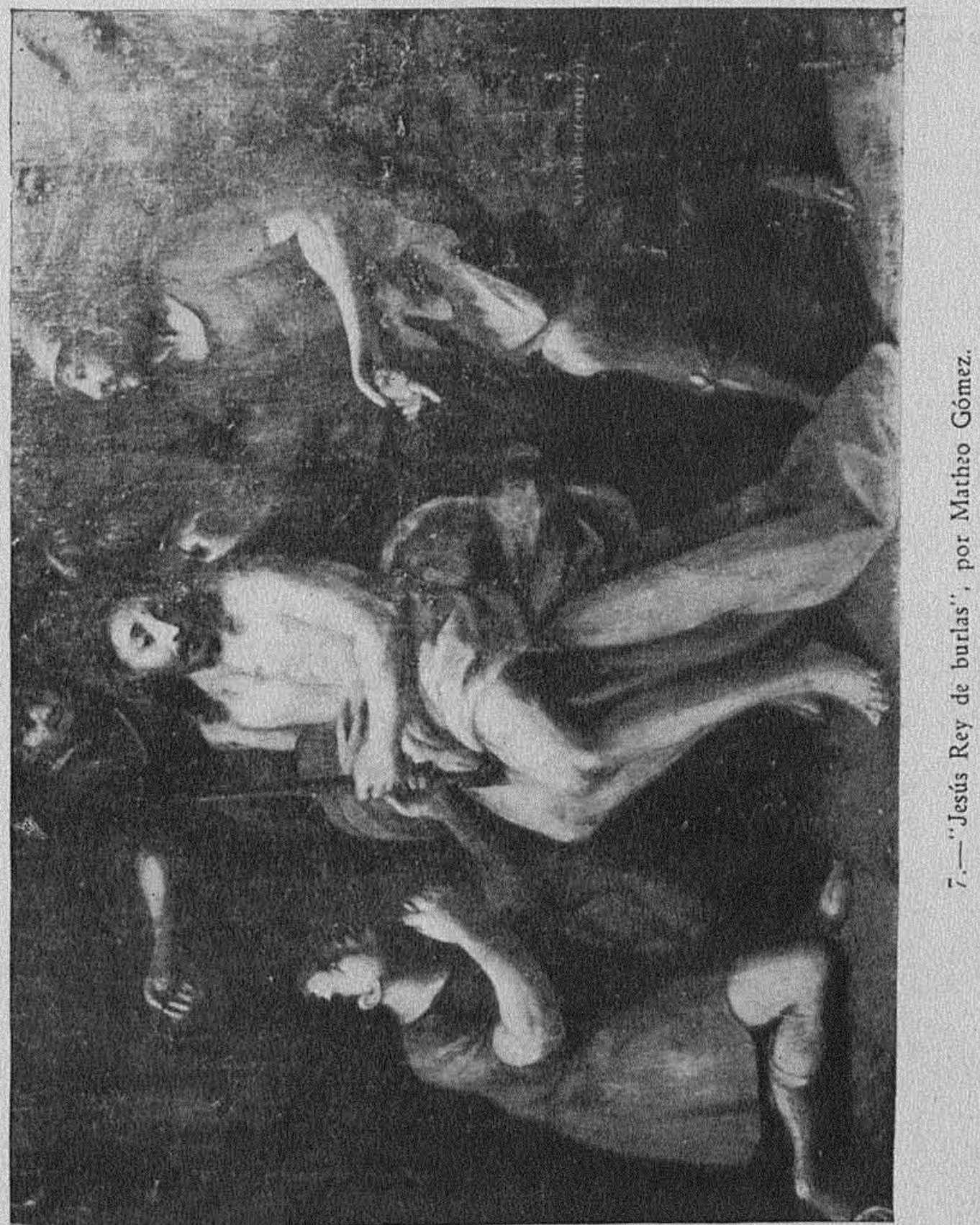




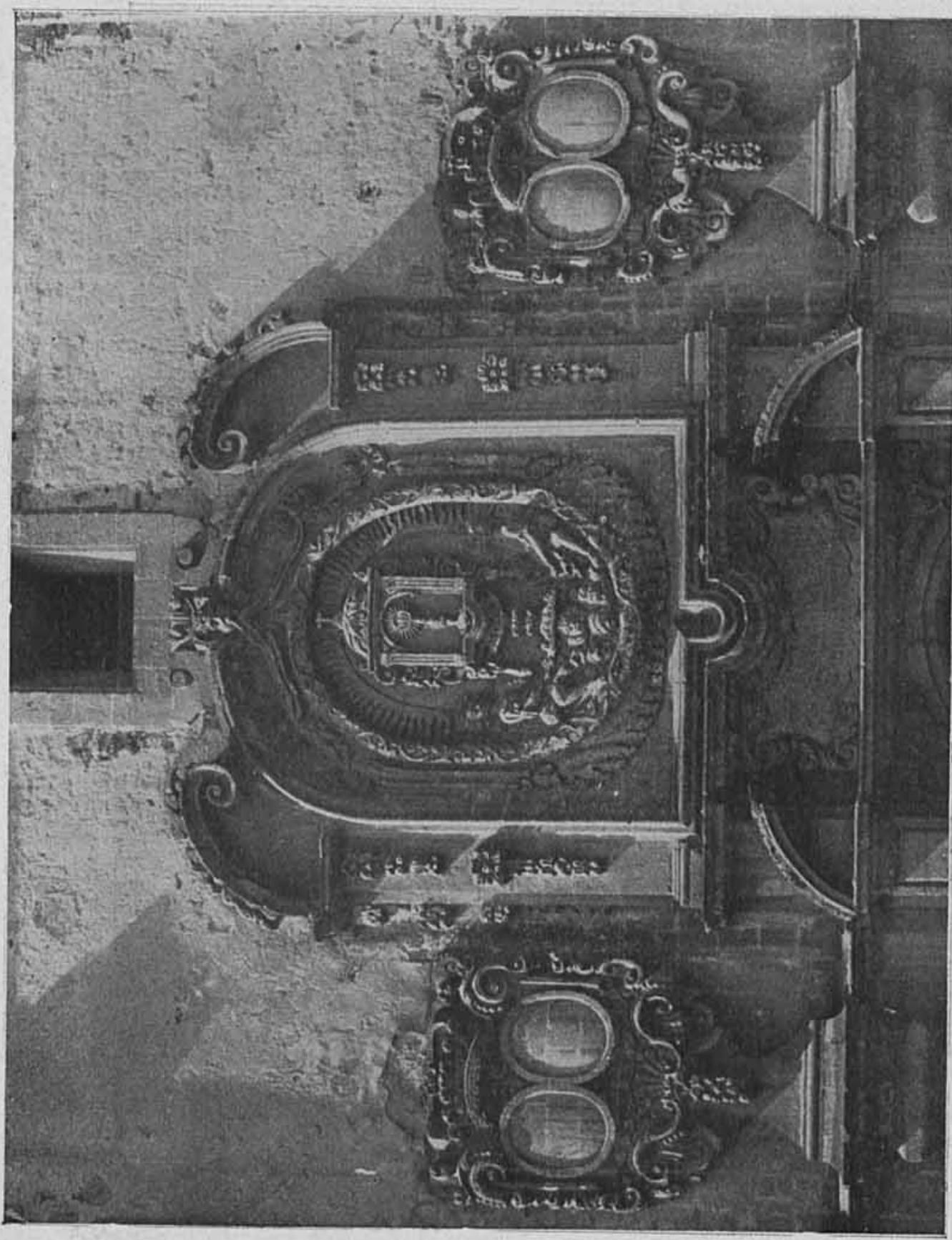

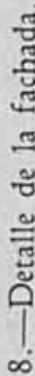




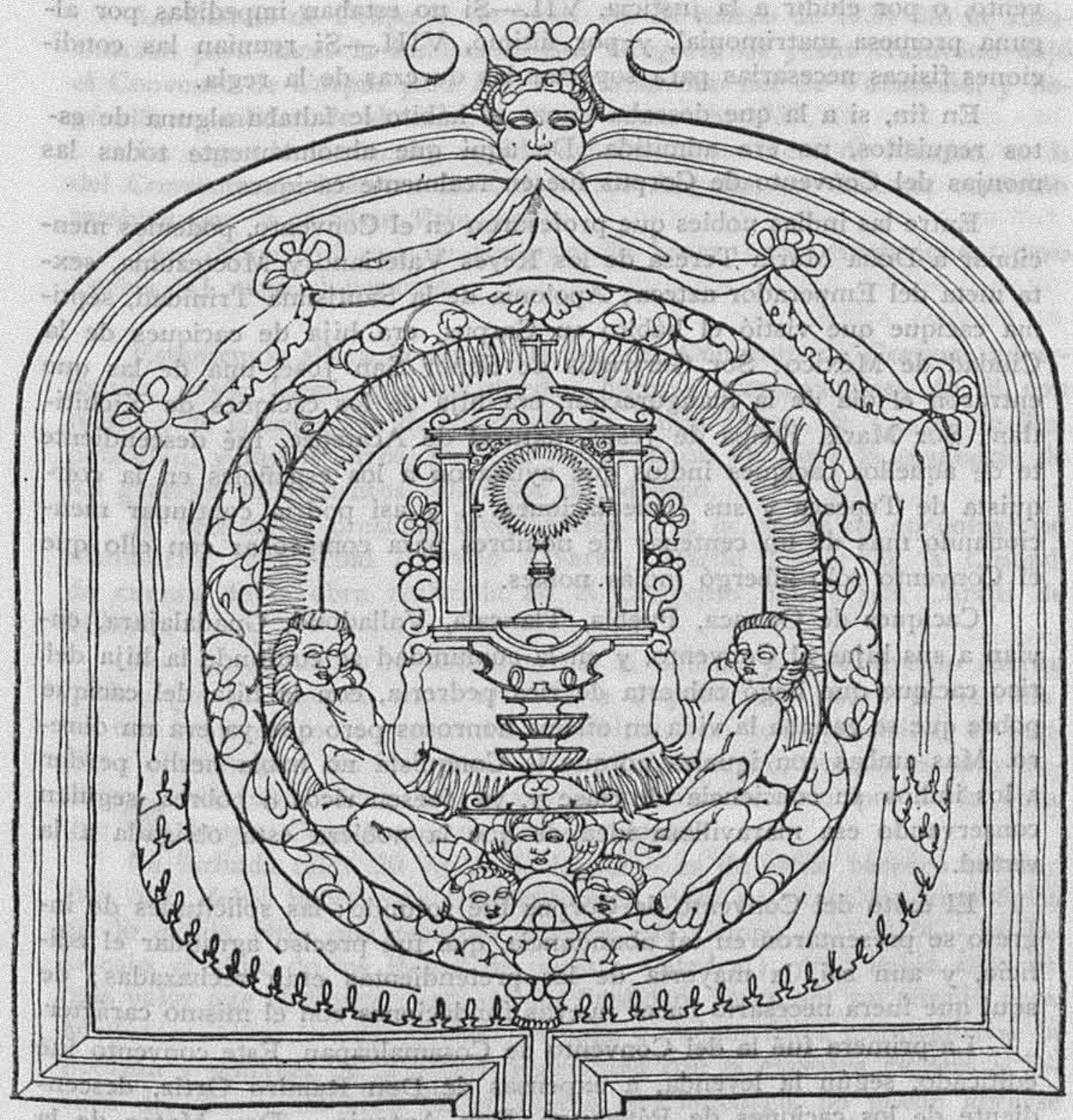

-TEMPIO-DE-CORPUS-CHRISTI DETALIE.DE.FACHADA. 
ascendientes procesados por el Santo Tribunal de la Inquisición. V.- Si eran hijas de legitimo matrimonio. VI.-Si no entraban forzadas al Convento, o por eludir a la justicia. VII.-Si no estaban impedidas por alguna promesa matrimonial, y por último, VIII.-Si reunían las condiciones físicas necesarias para soportar las durezas de la regla.

En fin, si a la que deseaba tomar el hábito le faltaba alguna de estos requisitos, no era admitida. De aqui que absolutamente todas las monjas del Convento de Corpus fuesen realmente caciques.

Entre las indias nobles que profesaton en el Convento, podemos mencionar a Doña María Teresa de los Reyes Valeriano y Moctezuma, sexta nieta del Emperador azteca; Ap̄olonia de la Santísima Trinidad, séptima cacique que vistió el hábito en Corpus, era hija de caciques de la Ciudad de México; Sor Gertrudis de Señor San José, una de las que entraron el día de la inauguración, era hija de los caciques de Xichititlan; Sor Maria Felipa de Jesús, natural de Acatepec, fué descendiente te de aquellos caciques indios que ayudaron a los españoles en la conquista de Tepeaca y sus inmediaciones... y asi podria continuar mencionando más de un centenar de nombres para comprobar con ello que el Convento sólo albergó indias nobles.

Caciques de Oaxaca, Puebla, Tlaxcala, Valladolid, Guadalajara, envían a sus hijas al Convento, y en la comunidad se confunde la hija del rico cacique que llegó cubierta de rica pedrería, con la hija del cacique pobre que se ganaba la vida en oficios honrosos pero que ya era un obrero. Mas ambas son iguales porque la Conquista no habla hecho perder a los indios su conciencia de clase y, ya fuesen ricos o pobres seguían conservando esa maravillosa idea de que la nobleza está obligada a la virtud.

E1 éxito del Convento de Gorptis fué rotundo; las solicitudes de ingreso se presentaron en tal abundancia, que fue preciso agrandar el edificio, y aun así, la mayoría de las pretendientas era rechazadas; de aquí que fuera necésario hacer nuevas fundáciones cón el mismo carácter.

La primera fué $\dddot{\mathrm{la}}$ del Convento de Cosamaloapan. Esste convento fué edificado, según la leyenda, a expensas de Don Ramiro Ortiz, descendiente de los caciques de Pátzcuaro, Don Antonio y Don Mateo de la Cerda; que años atrás. habían edificato la capilla de Nuestra Señora de Cosamaloapan. En realidad, históricamente, sólo sabemos que "una persona piadosa" dió ocho mil pesos para la construcción de un convento 
para indias nobles, y que este dinero se entregó a una monja del Convento de Corpus.

La Cédula de Felipe $V$ de fecha 14 de marzo de 1734 dió la autorización para hacer la fundación. Sor Gregoria de Jesús Nazareno dejó el Convento de Corpus para hacer la fundación del de Valladolid, y llegó alli, en calidad de abadesa, el 11 de marzo de 1737. 1

La segunda fundación, nacida del Convento Indio de México, es la del Convento de Nuestra Señora de los Angeles, en Oaxaca, conocido también por "Los Siete Príncipes".

Dice Marroqui que se trataron de hacer otras fundaciones, pero Carlos III negó el permiso.

Estudiemos ahora la obra artística del Convento de Corpus; advirtiendo, desde luego, que no pueden hacerse comparaciones de él con templos de la categoría del Sagrario, de Santa Prisca de Taxco, de Tepotzotlán, y tantos otros, pues su construcción no tiene la opulencia de los grandes monumentos religiosos de México.

Al realizar la presente investigación tuve la suerte de encontrar un manuscrito en el cual Antonio Alvarez, Alarife Mayor de la Ciudad, da cuenta de la obra realizada en el Convento de Corpus Christi de México.

Por este manuscrito sabemos que la Iglesia y el Convento fueron hechos por el maestro en el arte de la arquitectura Pedro de Arrieta; en este manuscrito se encuentran descritos, con toda precisión, el templo y el convento. Nó insertamos aquí el manuscrito, porque es muy extenso, pero, fundándome en él, voy a describir lo principal de la obra que nos ocupa. Comenzaremos por el templo.

La fachada mide 30 varas de frente y es de estilo barroco sobrio; esta obra debió haber sido churrigueresea, pues su situación cronológiça así lo exigia (hay que recordar que en este tiempo - 1720-24- se fabricaba el altar de los Reyes de nuestra Catedral), pero habia algo de más valor que el tiempo; esto era la finatidad. Iba a ser un templo para la obra mendicante más austera del pais, y ¿cómo iba a compaginarse la pobreza y sencillez de la orden franciscana con la excesiva riqueza y locura del churrigueresco? El arquitecto, sin embargo, no puede librarse del barroco, que es también un estilo rico y rebuscadō, porque una tra-

1 Estos muchos otros preciosos datos acetca de esta primera rama derivada de Corpus, los debo a la gentileza del señor Porfitio Martínez Peñaloza. 
dición de un centenar de años y un estado social "barroco" pesaban sobre él. A pesar de ello, saber dar a su obra el carácter que exigía el objeto para el cual se destinaba, creando un templo de un barroco sobrio, caracterizado por su poco relieve. La portada esta formada por un arco de medio punto entre pilastras y un frontón curvilíneo en cuyo centro hay una gran cartela con una inscripción que dice: ESTE CONVENTo DE RELIGIOSAS FRANCISCAS INDIAS HIJAS DE CACIQUES Y NO PARA OTRAS, SF EDIFICO $Y$ FUNDO ROR EL EXCEIENTISIMO SEÑOR DON BALTAZAR DE ZUNIIGA $Y$ GUZMAN SOTOMAYOR $Y$ MENDOZA, MIARQUES DE VALERO AYAMONTE Y ALENQUER, SIENDO VIRRIY, GOBERNADOR Y CAPITAN GENERAL DE ESTE REYNO, GENTIL HOMBRE DE LA CAMARA DE SU MAGESTAD Y OIDOR DE SU REAL AUDIENCIA.

Esta inscripción fué hecha en 1729.

En ia parte alta hay un gran medallón en altorrelieve, que representa una custodia con el Santísimo Sacramento, símbolo de la iglesia y del convento, ya que éste se llama "Corpus Christi", Cuerpo de Cristo. Todo el medallón está rodeado de adornos barrocos. A los lados se encontraban los escudos del Marqués de Valero, rodeados también de "foHaxe de Talla".

Sin embargo, estos aspectos barrocos no alteran la austeridad de la construcción, que se acentúa con las sencillas pilastras y el frontón clásico. A los lados existian grandes ventanas con sts rejas de hierro forjado.

E1 interior de la iglesia se encuentra, por lo que respecta a decoración y motivos artísticos, completamente destruído; sin embargo, indicaremos lo poco que queda de lo que fué y lo que sabemos de lo que habia entonces.

La iglesia tenía en su interior 12 varas de ancho y 24 de largo. Era de una sola nave con bóveda de cañón corrido, dividida en tres tramos "por grandes arcos de piedra de tezontle, con sus repisas de piedra de Chiluca y canteria".

En estos tres tramos encontramos primero el ábside, que es de forma poligonal, irregular, y se encuentra cubierto por una bóveda de mampostería sobre gruesos nervios. En la parte central tiene un ojo que le da luz.

En seguida encontramos la parte central dividida por pilastrones que sostienen arcos fajones. Sobre ellos se apoya la bóveda de cañón que, cosa extraña en México, era de madera. Esta bóveda se prolonga hasta el tercer tramo, que es el coro alto, y cuyo piso es de bóveda de arista. 


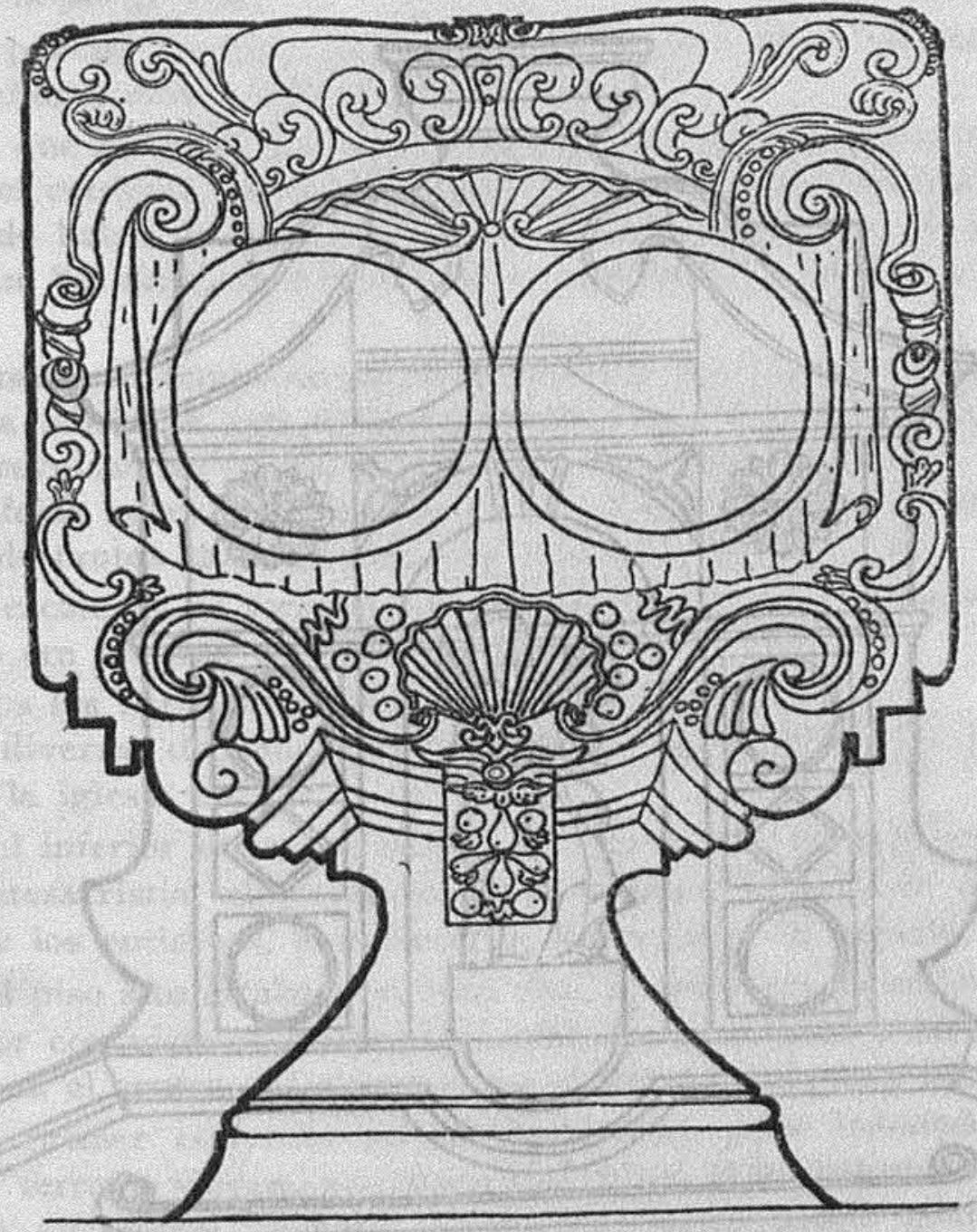

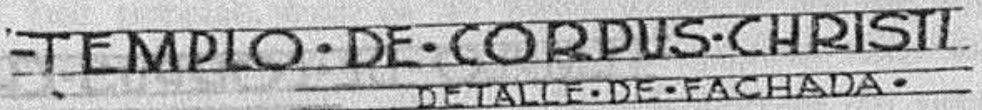


DOI: http://dx.doi.org/10.22201/iie.18703062e.1941.7.227

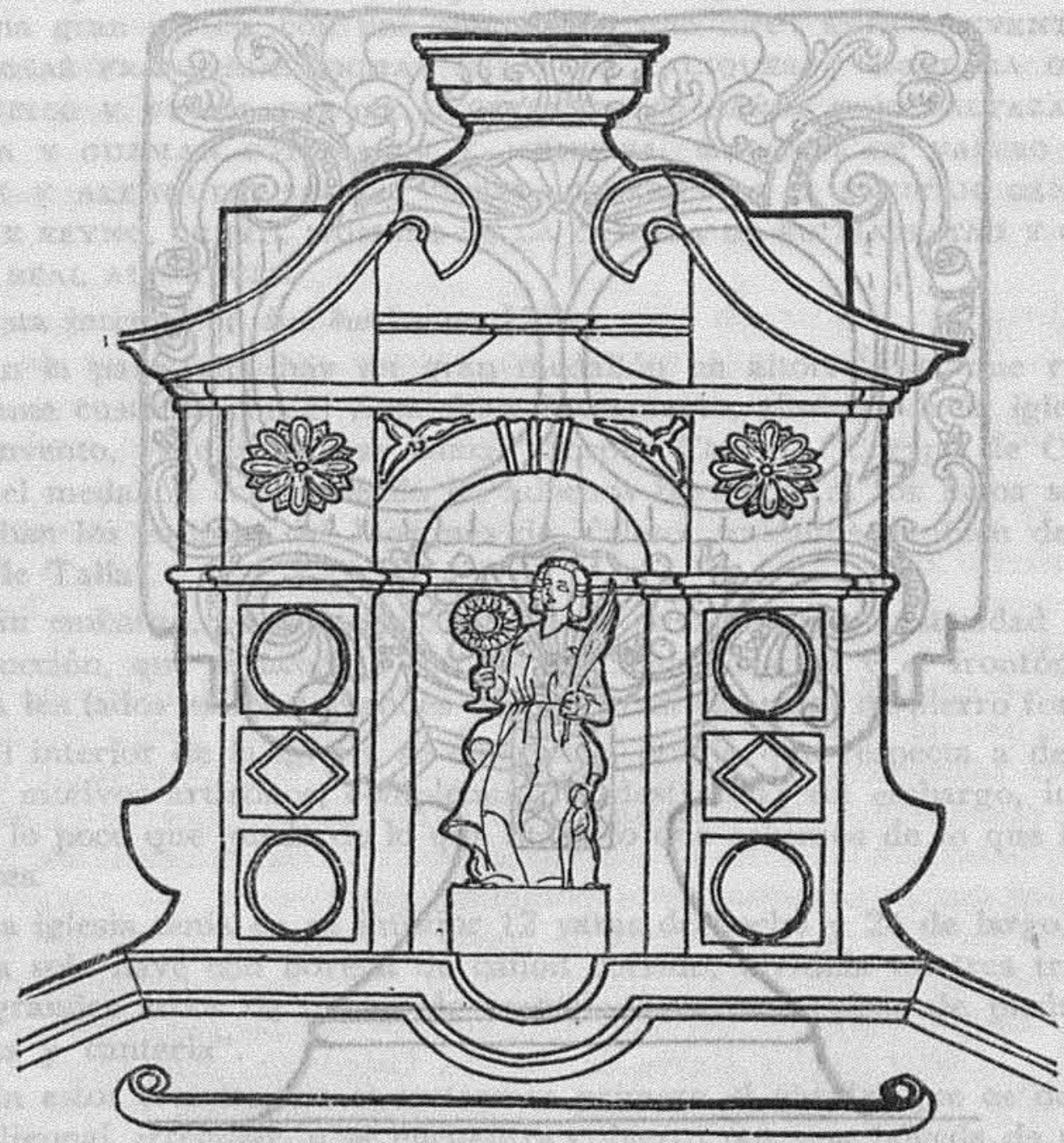

\section{-IEMPLO-DE-CODPUS-CHDISTI DE TALIH.FACHADA}


Habia en la iglesia "dos portoncillos con sus escaleras de mampostería, para dar entrada a las dos tribunas" que caían a la iglesia. Esas tribunas se encontraban en los ángulos de la entrada.

El coro bajo y el locutorio tenían sus rejas de fierro y sus contraIrejas de hojas de lata.

Las puertas y ventanas en la parte inferior eran "de media moldura con sus chumaceras y quicialeras de bronce".

Hay que advertir que el maestro Pedro de Arrieta no cumplió exactamente el contrato de la obra, pues hizo numerosas innovaciones, entre ellas, la de haber hecho una bóveda de madera cuando el contrato estipulaba que "el techo fuese de madera cuadrada" y que abarcase hasta el ábside.

El convento estaba construído todo con piedra de tezontle. El clanstro estaba fabricado con cuarenta arcos "de rosca de ladrillo y tezontle, con sus cornisamientos altos y bajos y su repisa" que los recibía. Este claustro debia haber sido de planchas de madera de cedro, pero no lo fué por uno de tantos cambios que hizo Pedro de Arrieta.

Las escaleras de todo el convento debieron ser de madera de cedro, pero sólo era asi una de ellas.

Todos los barandales eran de balaustres torneados.

Las diversas dependencias se hallaban repartidas alrededor del claustro $y$ de la iglesia en dos pisos.

En el inferior se encontraban: la porteria, la anteporteria, la sacristía, la antesacristia, el locutorio, el coro bajo, la sala de confesonarios, la sala de los entierros, el refectorio, la cocina y la ropería.

En el piso alto estaban : el coro alto, el antecoro, la enfermeria, la sala de labor con vista al jardín, el noviciado, las celdas y los servicios sanitarios; en el centro del claustro, en el patio, habia una fuente.

Este primer convento no lo conocemòs, ptres habiendo construído sobre un terreno virgen, es decir, sin háber sido endurecido por construcciones anteriores; empezó a hundirse haciéndosele grandes grietas, por lo cual fuế precíso que se le reconstruyese desde los cimientos en 1747. Se aprovechó la reconstrucción para hacerlo más amplio, añadiéndosele un nuevo patio. Este segundo monasterio es de menor mérito que el primitivo, su interés es sobre todo histórico, pues es allí en donde se desarrolló casi la vida conventual. El claustro es además muy pintoresco y llama la atención por el sitio en que se encuentra. Sobre estas obras de 
arquitectura, vinieron los pintores del siglo XVIII y cubrieron con sus magnificos lienzos el claustro, la sala de labor, el locutorio y la iglesia.

Entre las pinturas que pertenecieron al convento, señalaremos el "Jesús Rey de burlas", de Mathea Gómez.

El retrato del Marqués de Valero fué obra del notable pintor Juan Rodriguez Juárez; obras de este artista eran también los dos grandes cuadros del templo que representaban a San Francisco y Santa Clara. Había también las pinturas de las cuatro fundadoras, de éstas, la de Sor Antonia Micaela de San José y la de Sor María Gregoria de Jesús Nazareno (la hermosa monja que después de fundar Corpus, salió a la fun. dación del monasterio de Cosamaloapan), fueron obras del artista $\mathrm{Ni}$ colas Enriquez.

Los retratos de Sor Petra de San Francisco y Sor Teresa de San José no tienen ya firma, por encontrarsé casi deshecha la parte inferior de ellos.

A reserva de lo que cualquier manuscrito posterior nos indicará, podemos decir por la identidad de estilo, que el retrato de Sor Petra de San Francisco nos parece que fué hecho por Nicollss Enriquez, no asi el de Sor Teresa de San José, que es totalmente distinto đe los otrós tres.

Hay además una hermosa pintura retrato de la india "Sebastián Inés Josepha de San Agustín", hecha por el pintor Avila.

Este es uno de los cuadros más interesantes, pues siendo retrato de una joven de 16 años en traje seglar, nos muestra la riqueza con que las indias Ilegaban ataviadas al convento.

Existe también el retrato de la india Sor Juana Maria del Espiritu Santo, de quien dijimos que murió en la prișión. Este retrato no tiene firma.

Respecto a los ormamentos sabemos que los habia riquisimos, pues aquellas perias y aquellos chalchihuites con que las indias entraron al convento, fueron empleados en los adornos de ellos. Los ornamentos que hicieron las monjas tienen como cosa muy suya, la combinación extraña de los colores, hecho que nos manifiesta el concepto indigena de la policromia.

Además, sabemos que en el convento existian telares en los cuales se fabricaban riquisimas telas de oro y plata, con las que después se confeccionaban los ornamentos. 
Respecto de los vasos sagrados, creo que debieron haber sido muy ricos, pues el convento se vió siempre favorecido por las personas más nobles y ricas de la ciudad.

Fué famosa por su ríqueza, más que por su arte, la custodia del convento de Corpus; así lo fueron también algunos copones y cálices.

Lo que ocurrió con todas estas obras no lo sabemos, pues se han perdido desde la exclaustración; tal vez muchas de ellas se encuentren repartidas en diversas iglesias de México y muchas otras hayan sido fundidas.

\section{CONCIUSION}

E1 gobierno español fundó en 1724 este hermoso convento, dando una prueba más de su fidelidad a la declaración del Concilio de Trento, respecto a la igualdad de los hombres en su origen y destino.

La creación de un México independiente le conservó la vida y sólo desapareció cuando, en 1861, las Leyes de Reforma exclaustraron a sus monjas y convirtieron la obra material del convento en escuela de sordo-mudos.

Hoy el templo es un comercio de curiosidades mexicanas y será derribado junto con el convento dentro de pocos meses; pero antes de que esos muros, que albergaron a la más pura aristocracia india, desaparezcan para siempre, nosotros les hemos arrancado un bello secreto de su más intima historia. 


\section{CONVENTO DE CORPUS CHRISTI}

(Tomo II de Informaciones)

Año y No NOMBRE

47 Sor Francisea Tomasa de la Sma. Trinidad.

48 Sor Gu. irudis Camacho. *

49 Sor Ma. Ignacia Calletana.

49 Sor Ma. Josefa.

175750 Sor Ma. Cayetana Clara.

175251 Sor Juana Maria Mani.

175352 Sor Luciana Manuela.

175353 Sor Juliana Matia.

175354 Sor Ma. Petra de Sa. Francisco.
PADRES

Antonio de los Stos. Sandoval.

Magdalena de la Rosa.

Juan Crisóstomo.

Magdalena Gertrudis.

Ignacio Manuel Roa.

Antonia de la Concepción.

Pedro Rodriguez.

Matcela del Valle.

Lorenzo de los Reyes Mani.

Juana Ma. Chichitl.

Gregotio Palacios y Maldonado.

Ana M2. de los Dolores.

Gabriel Sánchez Ramírez.

Juana Sánchez.

Nicolás Ramírez.

Isabel Maria.

\section{LUGAR DE LINĀJE ORIGEN}

Santiago Tlalteiol- Caciques.

co.

Española.

Ozumba.

Caciques.

Amecameca. Caciques.

San Getónimo. Caciques. Fiscal

(Tlalnepantla).

Sanctórum.

Catiques:

Texcaco.

Caciques. Belero.

Yanbuitlán. (Oaxaca).

Caciques. Gobernador.

San Juan Bautista Caciques. Coyoacac.
Gobernador Fiscal. 
175355 Sor Ma. Lugarda del Sa. cramento.

1753 56 Sor Juana Matia de la Trinidad.

175457 Sor Ma. Teodora de Sn. Agustin.

175458 Sor Ma. Manaela Antonia del Corazón de Jeเús.

175459 Sor Juana Manuela Chimalpopaca.

175560 Sor Mónica Gaetan.

175561 Sot Ma. Nicolazia de Loreto.

175662 Sor Ma. Antonia Dorotea Pérez.

175763 Sor Ma. Loreto Garcia Santos de la Peña.
Francisco Antonio Martinez Chimalpopoca.

Ma. de la Concepción Rojas.

Salvador Gallegos.

Maria Magdalena.

Tomás Salazar.

Ma. de la Encarnación.

Domingo Valeriano de San Martín.

Antoniz López.

José Miguel Marcial Xitlał- Puebla. popoca.

María del Espiritu Sto.

Agustín Miguel.

Damiana Micazla.

Tomás de Aquino.

Micaela Gerónima,

Pedro Vicente Pérez.

Lorenza Ma. Gutiërrez.

Lorenzo Garcia.

Gertrudis de los Santos y Peña.

México.

co.
Ciudad de México. Caciques.

Tecolotlán.

Caciques.

Cuauhtitlán

Atzompan.

Caciques. Gobernador.

Gobiques. Gernador.

Caciques. Sombretero.

Caciques. Cantero.

Santiago Tlaltelol- Caciques.

\section{San Mateo Churn- Caciques.} busco.
Caciques. Tratante de tilmas.

Santiago Tlattelol- Caciques.

* Van con letra cursiva los nombres de las monjas que salieron del convento por habérseles comprobado tencr mezcla de sungre española, por motivos de sajud o bien por no agradarles la vida monástica. El "lugar de origen" se refiere a los padres. 
Año y No NOMBRE

175764 Sor Antonia Ciriaca Sánchez Mezinchi.

175765 Sor Ma. Felipa de la $\mathrm{Pu}$ rificación.

175766 Sor Ma. Manuela del Corazón de Jesús.

175767 Sor Sebastiana Inés.

176168 Sor Josefa Isidra Rodrtguez.

176169 Sor María Clara Tomasa de Sta. Gettrudis.

176170 Sor Florentina Sandoval y Espar̃a.

176171 Sor Inés Josefa.

176272 Sor Maria Antonia de Jesucristo.

176373 Sor Diega de Espinosa. Miguel Pablo Luna Josefa.

Antonio Salvador.

Nicolaza Pascala. Micaela Diega.

Mateo Alejo.

Tomasa de Dios.

Andrés Rodriguez.

Felipa Francisca,

Fálix Antonio.

Brigida Francisca.

Francisco Sandoval.

Manuela Victoriana.

Julián Pablo.

Manuela Antonia.

Juan de la Cruz

Isabel.

\section{LUGAR DE LINAJE \\ ORIGEN}

Juan Antonio Sánchez.

Ma. de la Concepción.

San Antonio de las Caciques. Hottelano. Huertas.

Calimaya.

Caciques.

Hortelano

Agustín de la Cruz Jiménez. Necatitłán.

Santiago Tlaltelol- Caciques. Gobernador. co.

Sant Andrés Saltengo.

Santa Ma. Ia Redonda.

Santiago Tlälelol. Caciques. Marquesotero. co.

Santa Cruz. Caciques.

San Antonio de las Caciques. Hortelano. Huettas.

Tepeji de la Seda. Caciques.

San Antonio de las Caciques Hortelano. Huertas.

San Esteban (Popotta).
Fundidor de la R. Casa de Moneda. 
DOI: http://dx.doi.org/10.22201/iie.18703062e.1941.7.227

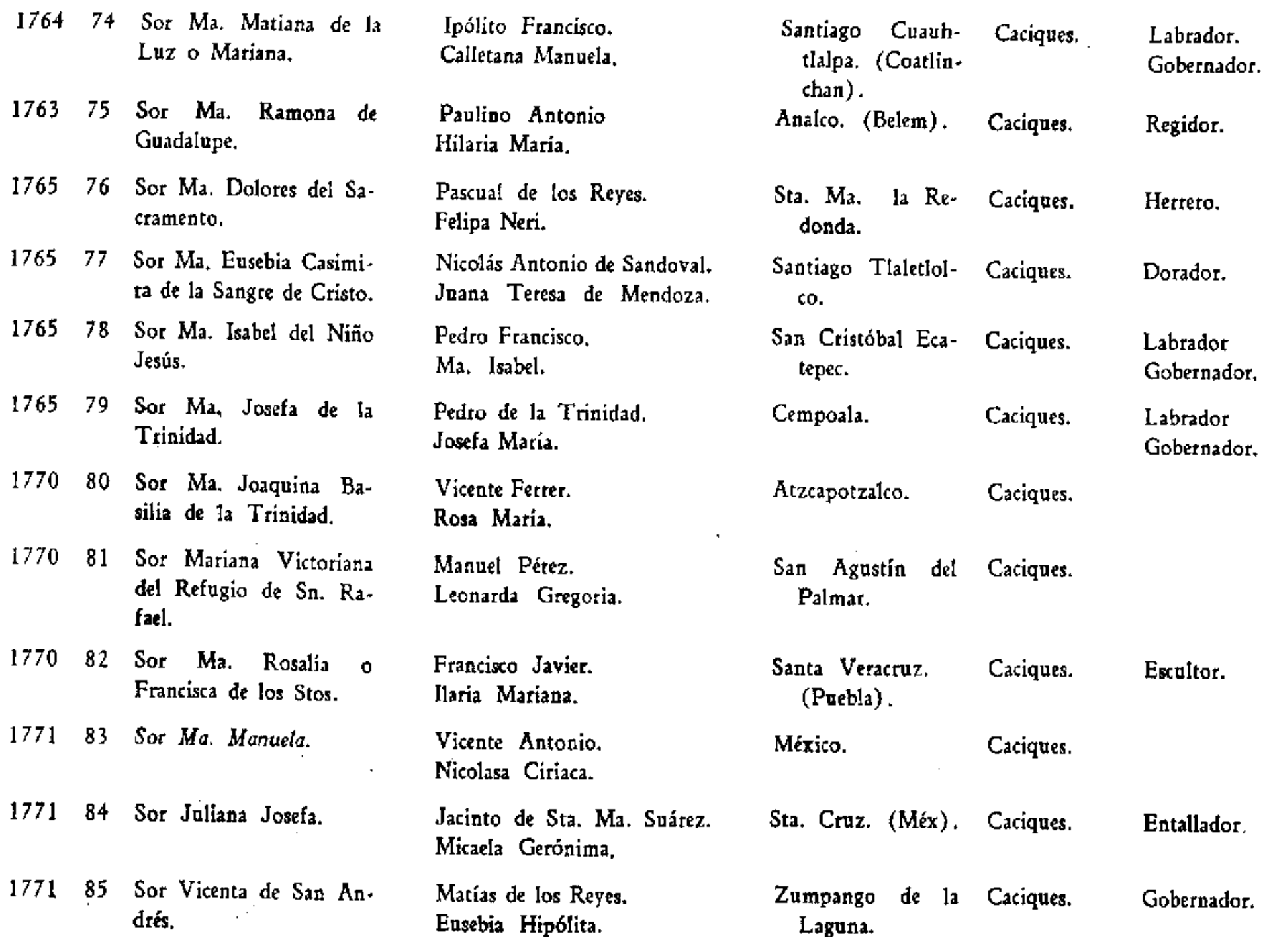


DOI: http://dx.doi.org/10.22201/iie.18703062e.1941.7.227

Año $y$ No NOMBRE PADRES

177286 Sor Francisca Dominga de Jesucristo.

177387 Sor Petra Josefa del Sacramento.

177388 Sor Ma. Tetesa de San Juan Nepomuceno.

177389 Sor Ma. Lorenza de San Miguel.

90 Sor Ma. Francisca Liberata de San Pedo Alcántara.

177791 Sor Ma. Gertrudiz Felipa de San Antonio.

177492 Sor Ma. Josefa Isabel Pérez.

1781 Sor Ma. Jimena.

1781 Sor María Ignacia de San Mignel o Ignacia Amador Juárez.
Pascual Avalos.

Mónica de la Bárcena.

Pedro Ramírez.

Petrona Pérez.

Francisco Sáncherez.

Juana Hernández.

Pedro Gatcía *

María Dorotea.

Juan José Zacatzin.

Agustina Micaela Páez.

Pedro de la Cruz Velázquez.

Sebastiana Teresa de la Pal-

ma.

Dionisio Pérez.

María Daniel Roxan.

Informaciones desde 1781 hasta 1867 .

Felipe de Jesús.

Ma. Antonia Lozano.

Nicolás Matias Amador.

María Briseño Juátez.

Alfarcan co.

\section{Acatepec.}

Tlaxcala.

\section{LUGAR DE \\ ORIGEN}

Sto. Tomás Ixtitlán, (Oaxaca).

San Miguel Amattán, (Oaxaca).

Santiago Tlaltelol-

Meca-meca.
Santa Ma. Acapa- Caciques. tlabuacán, (Atlixco).

Caciques.

Carpintero.

Nonohualco.

San Juan Bautista Xichu de indios. (San Luis de la $\mathrm{Paz})$. 
DOI: http://dx.doi.org/10.22201/iie.18703062e.1941.7.227

\section{Sor Petra Gertrudis. Lucas Bonifacio. Juliana Bautista.}

1781 Sor Aniceta Velazco.

1781 Sor Maria Faustina de la Encarnación o Ma. Guadalupe de la Trinidad.

1782 Sor Marcelina de los Dolores.

1782 Sor Victoriana de Santa Catarina o Catarina Quatecatl.

1782 Sor Bárbara de San Joaquín a Bárbata Antonia Pérez de León.

1782 Sor María Carina o Ma. Cirila Pérez.

1782 Sor Ana Gertrudis de! Sacramento o Ana Gertrudis de Castilla.
Miguel Velazco.

María Sáncbez.

Juan Roldán.

Catarina Xicale.

Pascual de la Cruz Montoya.

Ma. Josefa García.

José Silvestre Rodríguez.

Rosalia de los Dolores.

Lucás Kuatecat.

Simona Saucedo.

Francisco Pérez de León.

Mícaela Josefa de León Niño.

Juan Bonifacio.

María Buenaventura.

Clemente de Castilla.

Luciana Gertrudis Taimes.
Tulpetlaque.

Zumpango de la

Laguna.

San Juan Haitache. Caciques. Comerciante (Oaxaca).

Santiago Tlaltelolto.

San Andrés (Cho- Caciques. Labrador. lula).

Coyatepec.

Tepozotlán.

Caciques. Gobernador.

Caciques.

San Luis Nehuila- Caciques. cuca. (Cholula).

Acazingo.

Caciques.

San Isidro.

San Pedro de la

Caciques. Cañada.

Guachinango.

Apan.
Comerciante

Fiscal.

Gobernador.

en Harinas.

Caciques. Gobernador.

* Caciques descendientes en línea recta del Empexador Moctezuma. 
DOI: http://dx.doi.org/10.22201/iie.18703062e.1941.7.227

Año y No NOMBRE

LUGAR DE
ORIGEN

LINAJE

OFICIO

1782

Sor Simona María Co. rona.

Juan Corona.

Isabel Torres.

1782 Sor Ma. Calletana Alberta.

Félix Antonio

Brigida Francisca.

Nicanor Vicente Jiménez.

Antonia de la Trinidad Hernández.

Sor Antonia de ta Trinidad.

Bartolo Hernàndez de Luna. Lucía Rosa.

José Manuel Cerón.

Eusebia Teresa del Castillo.

Carlos Antonio

Zacarias Retama.

Manuela Leonarda Ximenes.

Antonio Motales.

Magdalena Persino.

Francisco Díaz.

Ma. Diega Fernández.

1787 Sor Ma. de la Luz Coscatl.
Pedto Antonio Cos
Atitalaquia.

Los Reyes. (Tlal- Caciques. Biscochero. teloleo).

San Miguel y San. ta Ana Xeloyzingo. (Tlanepantla).

Tlanepantla.

Caciques. Gobernador.

Santa Cruz. (Méx). Caciqques.

Belem. (Méx.)

San Ciprián.

(Doctrina de Sta. Cruz).

Caciques. Músico.

Cholula.

Gobernador.

Tlazilpa. (Doctri- Caciques. Albañil. na de Sta. Veracroz).

Sta. Ma. Tonan- Caciques. Alcalde. zintla.
Caciquaes.

Caciques. 


\begin{tabular}{|c|c|c|c|c|c|}
\hline 1788 & $\begin{array}{l}\text { Sor Felipa Juliana Se- } \\
\text { cunda. }\end{array}$ & $\begin{array}{l}\text { Aparicio de Guadalupe Juá- } \\
\text { tez y Mendoza. } \\
\text { Ma. Cecilia de los Reyes Moc- } \\
\text { tezuma. }\end{array}$ & $\begin{array}{l}\text { San Mateo Aten- } \\
\text { co. (Doct. de } \\
\text { Metepec). } \\
\text { Tlascuaque. } \\
\text { (Mex.) }\end{array}$ & Caciques. & \\
\hline 1791 & Sor Manuela Margarita, & $\begin{array}{l}\text { Juan Francisco de la Cruz, } \\
\text { Catalina Inés. }\end{array}$ & Tecomatlán. & Casiques. & \\
\hline 1791 & Sor Ma. Teodota. & $\begin{array}{l}\text { Julián Antonio Xis (?) } \\
\text { Tomasa Francisca Gutiérrez. }\end{array}$ & México. & Caciques. & Alcalde. \\
\hline 1791 & $\begin{array}{l}\text { Sor Fernanda Juana Sán- } \\
\text { chez. }\end{array}$ & $\begin{array}{l}\text { Vicente José Sánchez. } \\
\text { Gertrudis Rivera. }\end{array}$ & Santa Bárbata. & Caciques. & \\
\hline 1792 & Sor Gertrudis Gregoria. & $\begin{array}{l}\text { Cirilo Blas. } \\
\text { Matilde Rita. }\end{array}$ & $\begin{array}{l}\text { Santiago Zapotí- } \\
\text { tlán. }\end{array}$ & Caciques. & Gobernador. \\
\hline 1795 & Sor Josefa Aniceta. & $\begin{array}{l}\text { Gregorio Urbano, } \\
\text { Ussula Jiménez, }\end{array}$ & $\begin{array}{l}\text { San Buenaventuma } \\
\text { (Cuauhtitlán). }\end{array}$ & Caciques. & $\begin{array}{l}\text { Labrador } \\
\text { Tejedor } \\
\text { Gobernador. }\end{array}$ \\
\hline 1795 & Sor Gabriela Josefa. & $\begin{array}{l}\text { Manuel Daniel. } \\
\text { Ana Tapia. }\end{array}$ & $\begin{array}{l}\text { San Miguel Atita- } \\
\text { Jaza (?) }\end{array}$ & Caciques. & $\begin{array}{l}\text { Labrador } \\
\text { Gobernador. }\end{array}$ \\
\hline 1795 & Sor Inés Francisca. & $\begin{array}{l}\text { Andrés Basilio Juárez. } \\
\text { Sebastiana de la Cruz. }\end{array}$ & $\begin{array}{l}\text { Eloxachitlan. } \\
\text { Méx. }\end{array}$ & Caciques. & \\
\hline 1795 & Sor Francisca Panla. & $\begin{array}{l}\text { Manuel Luna. } \\
\text { Ana Ildefonsa. }\end{array}$ & $\begin{array}{l}\text { San Matías. (Doct. } \\
\text { de San Sebas- } \\
\text { tián). }\end{array}$ & Caciques. & \\
\hline 1800 & $\begin{array}{l}\text { Sor Ma. Cayetana Lo- } \\
\text { tenza de San Joaquin y } \\
\text { Marín. }\end{array}$ & $\begin{array}{l}\text { Miguel Marín. }{ }^{*} \\
\text { Rosa Pérez Azotla. }\end{array}$ & $\begin{array}{l}\text { Santiago, } \\
\text { (Puebla) }\end{array}$ & Caciques. & Gobernador. \\
\hline
\end{tabular}

* Descendiente de los Reyes de Tlaxcala. 


\begin{tabular}{|c|c|c|c|c|c|}
\hline Año y $N^{9}$ & NOMBRE & PADRES & $\begin{array}{l}\text { LUGAR DE } \\
\text { ORIGEN }\end{array}$ & LINAJE & OFICIO \\
\hline 1802 & Sot Juana Paula. & $\begin{array}{l}\text { Juan Patricio. } \\
\text { Melchora de los Reyes. }\end{array}$ & $\begin{array}{l}\text { San Juan Bautista } \\
\text { (Toluca). }\end{array}$ & Caciques. & Labrador. \\
\hline 1800 & Sor Ma. Josefa. & $\begin{array}{l}\text { José Felipe, } \\
\text { Ma. Trinidad Sänchez. }\end{array}$ & $\begin{array}{l}\text { San Felipe. } \\
\text { Santiago Atzcapot- } \\
\text { zalco. }\end{array}$ & Caciques. & \\
\hline 1804 & Sor Ma. Josefa Valeriana. & $\begin{array}{l}\text { Secundino Martin. } \\
\text { Crecenciana Perfecta. }\end{array}$ & San Martín. & Caciques. & \\
\hline 1804 & $\begin{array}{l}\text { Sor Ma. Josefa Nicola- } \\
\text { za Ocotlan Zarate. }\end{array}$ & $\begin{array}{l}\text { Felipe Neri Ocotin. } \\
\text { Josefa Zátate. }\end{array}$ & Puebla. & Caciques. & $\begin{array}{l}\text { Brañidor de Ro- } \\
\text { pa. }\end{array}$ \\
\hline 1805 & Sor Angela Francisca. & $\begin{array}{l}\text { Secundino Carranza. } \\
\text { Florentina Alejandra Sando- } \\
\text { val. }\end{array}$ & $\begin{array}{l}\text { Santa Cruz Aca- } \\
\text { tlán. (Méx.) }\end{array}$ & Caciques. & $\begin{array}{l}\text { Herrero. } \\
\text { Vendedora de } \\
\text { ' patas de cae- } \\
\text { nero }\end{array}$ \\
\hline 1806 & Sor Ma. Petra. & $\begin{array}{l}\text { Blas Antonio } \\
\text { Casilda. }\end{array}$ & $\begin{array}{l}\text { San Agustín de } \\
\text { las Cuevas. }\end{array}$ & Caciques. & \\
\hline 1807 & Sor Ignacia Alvarado. & $\begin{array}{l}\text { Ignacio Francisco Matías } \\
\text { Alvarado. } \\
\text { Maria Quiteria. }\end{array}$ & San Martín. & Casiques. & Labrador. \\
\hline 1819 & Sor Ignacia Josefa. & $\begin{array}{l}\text { Hûario Santos. } \\
\text { Ma. Juana Romulda. }\end{array}$ & $\begin{array}{l}\text { San Cristóbal. } \\
\text { Acatepec. }\end{array}$ & Caciques. & Labrador. \\
\hline 1825 & $\begin{array}{l}\text { Sot Petra Estanista Sa- } \\
\text { bina. }\end{array}$ & $\begin{array}{l}\text { Ignacio Fuentes, } \\
\text { Ma. Josefa Sánehez. }\end{array}$ & Atizapán. & Caciques. & \\
\hline
\end{tabular}


Del libro "Biografias de algunas religiosas".

\begin{tabular}{|c|c|c|c|}
\hline $\begin{array}{l}\text { Sor Antonia Pérez de } \\
\text { los Santos. }\end{array}$ & $\begin{array}{l}\text { Lízato Pérez de los Santos. } \\
\text { Nicolasa de la Concepción. }\end{array}$ & Puebla. & Caciques. \\
\hline Sor Rosa. & & Mezquital. & Caciques. \\
\hline Sor Rosa de Loreto. & & Capuluas. & Caciques. \\
\hline $\begin{array}{l}\text { Sor Apolonia de la Stma. } \\
\text { Trinidad. }\end{array}$ & & México. & Caciques. \\
\hline $\begin{array}{l}\text { Sor Ma. Gertrudis de Se- } \\
\text { ior San Josḱ. }\end{array}$ & $\begin{array}{l}\text { Diego Totres Vasques. } \\
\text { Ma. de la Asención. }\end{array}$ & Xochititlán. & Cacique \\
\hline $\begin{array}{l}\text { Sor Ma. Magdalena de } \\
\text { Jesús. }\end{array}$ & & $\begin{array}{l}\text { Tlaxomulco. } \\
\text { (Guadalajara). }\end{array}$ & Caciqu \\
\hline $\begin{array}{l}\text { Sor Ma. Felipa de Je- } \\
\text { sús. }\end{array}$ & * & $\begin{array}{l}\text { Acatepeque. } \\
\text { (Puebla) }\end{array}$ & Caciques. \\
\hline
\end{tabular}

* No ea oficio vil porque tiene operarioa que las taven, pelen, etc. 


\section{A P E N D I C E}

\section{CARTA DE FRAY ANTONIO GUTIERREZ, DE TLALTELOLCO, PIDIEN- DO LA ERECCION DEL CONVENTO DE CORPUS CHRISTI}

Mny poderoso señor:

Por orden de V. A. recibo un mandato de nuestro gran Rey y Señor Felipe $V$ (que Dios guarde) para que diga lo que según la 'experiencia, trato y práctica en el manejo de los naturales de esta Nueva España, que como su cura he tenido en orden. asi las nacionales de ella (esto es, las Indias) puedan ser zeligiosas de la Gran Matriarca Santa Clata. Mirando tan religioso dictamen advierte mi respecto que cuando intentó el Rey Sobetano de cielo y tierra fundar en nuestros corazones su santa ley para las obras insignes de su prerrogación en el heroico acto de teligión de la abnegación de nuestra voluntad nos pone por San Lucas una misteriosa parábola de un príncipe que con el convite de unas bodas excita a los actos virtuosos de peligión cristiana; excúsanse Ios más al introito magnífico del convite; insta como misericordioso Rey a que se adjunten y los más con terrenas ocupaciones no quieren gozar de tan excclente bien et reversus servus nunciavit haec Domino suo y qué responde el señor como principe y como católico? exi cito in platear, et ricos civitatis et pauperes introduc hunc. Insta el fervor del siervo. factum est ut imperasti. Manda el dueño por segundo decreto exi cito in vicos, et seges, et conipelle cos intrare, at impleatur domus mea y que fué lo que del mandato se siguió? ibant turbe multe cum es: en donde pregunta San Jerónimo para qué fué toda esta parábola? y responde el santo con el evangelista: para fundar una religión cristiana y muy devota, si quis venit ad me et non odit Patrem suum et Matrem et uxocem et filios et fratres adhuc autem, et animam suam. non potest meus esse discipulus: con que para fundar pregunta si quis, para establecer lama exi cito, y a quiénes? A los pobres miserables ;Oh santo rey! iOh magnifico príncipe! que no aceptas personas non est acceptator personarum porque quiere este que se cumpla la voluntad de Dios vult Dheus ommes salvos fieri, y así a todos llama, ut impleatur domus med. No es otra con lo que venera mi respeto en el asunto presente, mirando el ardiente celo para que no vivieran quejosas estas nacionales am- 
pliándose sus favores a los varones se restringieran al femenino sexo. Señor, ya entán todas las nacionales convocadas para ser religiosas dixit servo suo, ya está todo prevenido nunciavit Domino suo, solo falta la licencia ut impleatur domus mea. Como obediente siervo pretendo dar el lleno al mandato $y$ así digo:

Que son las nacionales de esta septentrional de Nueva España (hablando en to genérico de ellas) muy pobres. muy humildes. muy recogidas y muy cortas de espíritu, pues por su pusilanimidad no se atteven a emprender empresas admírables, sien. do su mayor ruina la omisión hija de la cortedad de ánimo que les asiste, pero no careciendo por eso de ser sujetos muy capaces, idóneos $\gamma$ aplicados para cuales quiera obras espitituales como to experimentamos en lo temporales cargos, $y$ no tiendo esta si aplicación de estos nuestros tiempos porque leyendo en el R. L. F. Juan Bautista. religioso minorita, hijo de esta nuestra santa provincia en que trata de la aplicación e idoneidad de los indios, virtud y letras en Jos que estudiaron $y$ se enseñaron en este colegio real de Santa Cruz fundado en esta parroquia de Tilaltelolco que hasta hoy duran ous edjficios anoque se acabó la práctica por haberse fundado el Colegio Seminario y ver y leet las cartas latinas con tanta elegancia y propiedad, que parecen elocuentes ciceronianos, siendo muy observantes católicos y religiosos cristianos y en todas sus operaciones verdaderos levíticos por al cultivo que tuvieron de nuestros primeros religiosos en el ejercicio de las letras, ayudándoles a exponer las sagradas escrituras, misterios de fe, doctrina cristiana $y$ oraciones devotas como lo confiesa dicho $R$. P. por los años de 1604, en que flarecieron infinitos indios en virtud $\mathrm{y}$ letras y si así recién convertidos producian el fruto; contemple V. A. hoy en día que tales estarán? con más frecuencia, con más maestros, con mayor práctica y trato con los españoles. Pro. posición ilativa es esta a que respondo que los que se aplican muy buenos de que tengo sobrada experiencia. Acordaba y confundia mi espiritu el alabar a las nacionales y atender a la definición en la natural inclinación del sexo femenino: mulier magis invida et querela et magis maledidentior, et modatior est. Confímala el sabio. Melior est iniquitas viri, quam benefaciens mulier. Menos mala es la maldad del bombre que la bondad de la mujer. Genética es la proposición pero como no hay regla sin excepción entra la exposición de Jacenio que la modifica con la experiencia que tenemos de que están completas las historias de varoniles majeres que excedieron en santidad, virtud y fortaleza a la mayor firmeza del homberedicando sus vidas por víctimas de su alma, ofrecian firmes sus cuerpos a lo fuerte de una clausara, a lo duro de un cucbillo, a lo fogoso de las llamas, por no declinar contra 8 a dueño $y$ siendo esto asi, como es, son excepción de la regla las buenas, pues con la gracia de Dios no hay imposibles. non est impossibile apud Deum, pues con la experanza del favor divino en que todos aguardamos. veremos lo que Isaías decía: qui sperant in Domino mutabunt fortitudinem, assument pennas, sicut Aquila current et non Jaborabunt; ambalobunt, ef non defficient.

Asiento por asunto $y$ siento por conclusión que son ias natarales (según lo supaesto) sujetos muy idóneos y capaces para entrar y profesar en teligión porque son por su naturaleza constantes en sus propósitos, muy observantes en las tradiciones en que las pusieron en la ndeva conversión, teniendo por ptáctica por lo firme de ánimo que son que en diciendo en su idioma zemicacuihqui, que quiere decir: a sido costumbre, no los contratara todo al mundo, viviendo como viven en el santo temor de 
Dios de donde infiero ser sujetos capaces para el voto solemne de religión gne lata mente probare.

Dicen el Sr, Dr. S. Buenaventura, S. Tomás, Scoto, Ricardo, Durando, Bona. cina citados por el L. Villalobos que el voto de religión que se hace a Dios por promesa mejor que su contratio votum est promissio Deo facta de meliori bono, hablando con la práctica del cura ministro de indios en la experiencia de diecisiete años de administración digo que entre uno y otro sexo siendo ellos buenos, son mejores ellas por aer más bumildes, más pobres, más recogidas, más trabajadoras, pues las que casadas son me consta generalmente hablando que del sudot y trabajo de su rostro mantienen, sustentan, visten $y$ quidan a sus esposos, y que muertos ellos son tan fieles y constantes que sucede en la práctica interior de la confesión examinándolas por el estado si circa carnatia han tenido alguna distracción como hijas del frajil barro del damacesno campo a que en su idioma me ban respondido: Ah muy arnado padre mio, no lo quiera Dios que yo lo ofenda ni a El mi marida le quebrante su palabra, pues cuando nos juntamos le dí palabra a la purisima y siempre doncella Maria Santisima de no juntarme con otro y hasta hoy lo tengo amor a Dios primero y a mi marido muerto. Las que son doncellas guardan las tradiciones bebreas de no reirse con los hombres, de ayunar los sábados, sin obligarles pareciéndoles ser pecado de confesar $y$ comulgar las Pascuas con tan austero ayuno que puedo decir es al traspaso $y$ esto es general en todas para honra y gloria de Dios. Habiéndoles pues enseñado el ayuno natural (que es necesario para recibir el Eucarístico Sacramento) nos consta de su observancia que les dura el ayuno coarenta horas comiendo la víspera al medio día hasta las cinco o las seis de la tarde del día que ban recibido al Santisimo Sacramento no prueban bocado, ni ese dia comen carne solo beben un poco de chocalate cosa que en todo el año lo prueban y la que por necesidad de preñez, enfermedad o sed la tarde o noche antes de comulgar comieron pan o tortilla o bebieron agua, en la reconciliación to confiesan por culpa, preguntando puedo comulgar porque anoche o ayer tarde me lo moria pos agua o me to moria por comer. no haciendo esto por ignorancia sino del santo temor de Dios que tienen, la gran reverencia con que preparan sus cuerpos para comulgar siendo tal que ese dia con ninguno hablan, estándose en la iglesia hasta las doce por lejos que vivan, con los ojos bajos, los brazos crazados, de uno en uno sin hablar unos con otros como tengo dicho, poniendo en las entre calles unos sabumadores con lumbre, incienso o copale, saliendo otros de las casillas con los mismos instrumentos a perfumaries los pechos por las especies que acabaron de recibir. IOh fe santa! jOh Santo Dios! y como se engrandece tu gloria entre estos miserables, pues cogieron con tanto amor su fe que ellas principalmente son las primeras en las doctrinas, en las cuentas, en las congregaciones, en la misa $y$ en acudir al cumplimiento de cristianas, muy fieles con su obligación. y esto colo con el continuo cultivo de la doctrina cristiana y como dicho tengo que son mejores ellas que ellos, siendo sabido que quien puede lo más puede lo menos, siendo de mayor grado el orden sacerdotal que al voto de religion que es inferior, a ellos que no son tan buenos se les concede do más ¿pot qué a ellas siendo mejores no se les a de conceder lo menos que es el voto de religión?, luego razón será por útil a sus almas bien a su república y consuelo espiritual suyo el que les conceda el ingreso en clausura porque si solo con el ejercício de la doctrina cristiana viven como vemos que se aguarda de 
su constancia, fidelidad y firmeza con que siempre viven cultivadas con la oración, meditación y contemplación con que se ejercitan en los monasterios, ¿qué se aguarda?, nn catálogo de santas. Ojalá lo publique la fama para que en tiempo de nuestro Felipe bajen la cerviz las glonias de Macedonia y se eleven y sublimen las de España.

$V$. A. me perdone lo lato de mis toscos borrques y présteme paciencia que a quien pregunta es fuerza que le respondan para no dejar escrúpulo en que tropezar ni instạncia que no alcance en algún modo a responder. Cinco condiciones ponen los teólogos para lo formal del voto solemne de religión; que sea voluntario, de sujeto capaz que se haga a Dios, que sea libre y que sea mejor que su contrario, todas por la experiencia sabemos concurren en un national pero quiero sepa V. A. cuantas son cinco en las indias. Es doctrina de señor San Agustín con todos los teólogos que para merecer o desmerecer se requiere el acto voluntario teniendo este todo su principio intrínseco en el conocimiento del fin voluntarium est cuius principium est intra cum cognitio ne finis. siendo asentado por el filósofo nibil est in potestare voluntatis quam psa voluntas. que annque con decir que era rationales era suficente to traigo por necesario, porque dicen que los indios son inconstantes en sus dictámenes $y$ pareceres de donde se infiere el no ser firmes en lo volantario. A lo cual respondo que en lo que toca a las operaciones externas es verdad, en las internas es falso, pues en el santo sacramento del matrimonio se experimenta la prueba, siendo lo voluntario según el concilio conditio sine qua non luego no carecen de él para el ingreso en la religión. Son libres esta condición dice Escoto citado por Hago Cabello que es de dos maneras la libertad, de contrariedad, $y$ contradicción, porque annque algunos dicen que 10 mismo es libre que voluntario estando en tal sentencia babiendo probado lo voluntario se infiere lo libre hay otra libertad que procede de servidumbre y esta es de dos maneras como dice mi $\mathbf{S}$. D. Scoto. duplicem servitute naturale et legalem siendo cierto también segúa mi Subtil doctor que de ley natural todos nacen libres quod de lege nature ommes nascuntur. liberi, de la cual no hablo solo si de la legal y según lo dicho se infiere que las indias tienen la dicha servidumbre legal y teniéndola no pueden entrar en religión por ley real impuesta por el tributo gozan la servidumbre legal disminución de la Real Hacienda, porque cesado el tributo cesa la contribución, cesando la contribación fuerza es se disminuya la Real Hacienda porque aunque ellas no pagaran perdía el Rey el derecho a la especie que se disminaye luego según esto no pueden ser religiosas supuesto que no son libres, según el filósofo quod servis non polest exercere actus virtutis, pro eo quod oportetad preceptum Domini exercere axtus serviles, y que enclaustradas las indias se disminaye la especie en la prole que es contra Ia Real Hacienda, luego no pueden hacer voto por temer la servidumbre legal y no tener la libertad necesaria para el camplimiento del voto consta también del S. D. Scoto pretecea favorobilior est professio religionis quam. Matrimonis carnale; sed servus non potest profiteri religione sine voluntate Domini: igitur ne matrimanium contrahere, la mayor es verdadera la menor se distingue servus qui est Domini secundum omnia concedo, secundum aliqư, et nui iuris negó lnego según lo dicho se infiere que es esclavo puede hacer voto esto es el que lo es secundum aliqua es sui iuris, foera que el legislador que impone la ley la puede relajar según su voluntad, como consta de la menor que puede el siervo con licencia de su dueño bacer voto de religión luego siendo serviles a $S$. M. pnede ampliar este favor y concederles siendo sus siervos legales secundum aliqua et sui iurit, la merced para 
que puedan en religión para que sean sujetos capaces de profesar en ella siguiénđose de ello el servicio a Dios Nuestro Señor y bien a sus almas cuando lo vemos ampliados en los varones en los caciques $y$ señores ascerdotes como favor $y$ merced que bizo la real corona favores sunt ampliandi pene vere restringendi.

Que sea la condición del voto promesa a Dios deduzco lo que tengo dicho del santo temor de Dios, viviendo en él como viven, que aunque dicen ser gente sin temor, honor y vergūenza, las conveniencias humasas los han privado no siendo cierto lo que el valgo dice en todos que viven sin vergüenza y sin miedo, constándome 2 mí como su ministro to contratio, teniendo en esta mi feligrecía indias muy honradas $y$ temerosas de ambas majestades. La última condición es que el voto que se hiciere sea mejor que su contrario y siendo mejor el acto de religión que el de matrimonio por 1o anexo al voto de castidad, luego es mejor el acto de religión que el de matrimonio que aunque San Pabio dice: Melior est nubere quam viri, tengo por cierto que la que padiere vivir en continencia sea religiosa. Insta el discurso que como podrán observar tener $y$ tener en el ingreso de la religión el voto de castidad, razón que me ha desvelado por ser esta nación tan cálida $y$ para descargo de mi conciencia en lo que roca en lo exterior consulté varios doctores acerca del calor de los indios, diciendo que son calientes por naturaleza no de natural, siendo de sanguineo humor: quia cator sanguinis non exitat luxuriam intrinseco sed calor sanguinis nimitu misceatur cum aliquio humore vilioso, seu melancolico: luego según esto no le obsta a las naturales de esta región el ingreso en el acto beroico de religión. Pruebo prácticamente todo lo dicho en los actos interiotes del sacramento de la penitencia y digo: que no son muy frecuentes en esta culpa porque aunque por pecado genéricamente se toma toda maldad a los indios les parece que solo es pecado el que se comete carnalmente y solo a este le dicen Tlatlacole, que quiere decir pecado, y exhortándoles en su iđioma a que si tienen otro pecado que confesar vaelven muy fervorosas y dicen: No lo quiera Dios que no lo he cometido ni quiero cometer, y así digo que aunque son de naturaleza cálida son muy puras y muy castas, pues lo continuo es el no caer en tal culpa pues confesándolas continuamente infinitas $y$ sin número son las que en tal culpa no han caido, siendo verdad esta que reservo para el tribunal de Dios, luego por su naturaleza cálida no les impide el voto de castidad. No las quiero hacer tan puras que no carezcan de tribulaciones: tribulationem ramen carnis habebunt huismodi ego aute vobis parco. Pruebo a paritate el que no les impide su cálida naturaleza el voto de castidad.

En esta jurisdicción de Santiago Thatilolco hay muchísimas congregaciones del colegio de San Gregorio con la advocación de Nuestra Señora de Loreto que con grande esmero y celo tienen los muy reverendos padres de la Compañía de Jesús en que las más congregantes son doncellas, babiendo becho voto de castidad promesa a Dios Nueatro Señor mediante la Purisima Maria de Loreto mi señora viviendo estas tan abatraídas de lo mundano en las casilias de sus moradas que parece no haber tales nin̆as, en su edad macha compostura, en el hablar modestia $y$ en su voluntad mucbo obediencia que aún estando en el siglo confundirán a las más observantes religiosas. siendo su número de más de sesenta las de mi jurisdiccón, y su edad que la menor no llega a los veinte pasando basta los cuarenta, cosa que aunque me sirve de descanzo a! 
Verlas me aumenta la confusión a mi estado el ver unas niñas que sin obligación a la mayor petfección estén con gran perfección.

Comunmente hablando son tenidos Jos naturales por muy ebrios, siendo este vício raíz de muchas maldades pero hago en él grandisima distinción porque aunque en la gentilidad de estos naturales se castigaba este vicio con pena de la vida y a la hembra que bortacha apresaban la infamaban con toda su descendencia y siendo hoy cierto en su cristianismo lo desenfrenado con que viven por este vicio, ellas de ninguna manera lo beben, constándome en su vida interior que la que por necesidad, preñez - enfermedad ba bebido, se acusa de ello en la confesión con gran multitud de lágrimas, como sí hubieran cometido un gravisimo pecado. Y me ha sucedido el teprender a algunas casadas por haberlas visto con alguna frecuencia en la embriagnez 7 responden el no ser calpa suya sino violencia de algunos imprudentes marios que han solido llevar a la taberna con empujones, puriadas y violencias, luego aurque el vulgo las tenga por ebrias a mí como su pastor me consta el no usarlo luego no es condición que les pueda impedir el voto la religión $y$ así sóy de parecer mirando lo que veo el que son sujetos capaces para hacer voto solemne de religión por hallarse en ellas como ballan las cinco condiciones para to formal del voto de religión siendo recogidas por su naturaleza no tendrán demérito en la clausura may obedientes a sus padtes espirituales y en especial (puedo decir) a mi que las administro con que serán observantes en el voto de la obediencia. Muy pobres porque aunque algunas lo han por naturaleza por ser miserables de otras me consta lo son de espiritu porque aunque sus padres tengan caudal ni se componen, visten $\mathrm{y}$ aliñan ni lo desean, porque lo tienen por vanidad, salvo el dia que ban de recibir el sacrosanto cuerpo de Jesuctisto que entonces be ponen lo mejor que tienen luego no serán transgresoras del voto de la pobreza. Son peras y castas como lo tengo latamente probado luego según todo lo alegado $y$ probado ballo ser muy conveniente y útil para el servicio de Dios. Otro si que me pueden objetar el que son hábiles para las cosas mecánicas y he experimentado en varias niñas que quieren ser religiosas como se han aplicado a lear y escribir latín como consta por una carta que tengo de la muy reverenda madre sor Petra de San Francisco religiosa del convento de San Juan de la Penitencia exabadesa conocida más por su virtud que por su oficio teniendo a gran vanidad sus letras en que me afirma la grañde idoneidad de todas, constándome a mí de algunas que mejor leen el latín que bablan su idioma natural, y según todo to dicho suplico a V. A. se sirva de informar a mi Rey $y$ señor lo necesario que es para el bien de sus almas, de la república y servicio que a Dios Nuestro Señor se hace porque en algún modo le desagravie esta nación ofreciéndose estas niñas a ser cándidas axucenas en el claustro de la iglesia ofreciéndose así por las muchas que en su antigüedad al demonio sacrificaban pues refiecea jas antigüas historias que en este pueblo de Xaltilolco que quiere decir Montecillo de arena adoraban al ídolo Huichiloposti con tanta ceguedad y crueldad que de año a año se numeraban más de trescientas doncellas, saćándoles vivas el corazón por las espaldas, con cuya sangre victimaban a su falso dios. Pues ahora señor salga el corazón por la boca prometiendo a Dios sus almas para desagraviar las mil ofensas de sus ciegos antepasados. Este es mi parecer (salvo meliori). Colegio y parroquia de Santiago Tlaltelolco y mayo trece de mil setecientos y veintitrés años. 
Muy poderoso señor.

Besa la mano de V. A. su más favorecido capellán.

Fr. Antonio Gutiérrez,

Cura Ministro.-- (Rúbrica).

Ramo de Historia.

Tamo 109. VQ Fs. IIrto, a 13 vo.

\section{PARECER DE FRAY IGNACIO GARCIA DE FIGUEROA SOBRE EL MISMO ASUNTO}

Muy poderoso señor:

Fray Ignacio Garcia de Figuetoa, de la orden de nuestro Sr. San Francisco, Pro. visor General y vuestro eura ministro de esta parroquia de San José de Naturales, sita en el convento de nuestro señor San Francisco. de esta ciudad de México, primitiva de la América, obedeciendo el mandato de $V$. A. en que me manda que informe de las conveniencias $e$ inconveniencias que se podrăn seguir según la ley 1, título 3 del libro 1 de la Recopilación de las Reales Leyes de Indias, acetca de la fundación del convento de Religiosas Descalzas de nuestro señor San Francisco, para las indias principales y nobles de este reino, digo: que para la dicha fundación, hay la justa causa y urgente necesidad que mandaba sobre dicha ley, porque habiendo muchas indias de conocida virtud y que algunas y án las más de ellas no aprovechan en la virtud con la perfección que pudieran por falta de recogimiento religioso que pide la vida espiritual $\mathrm{y}$ mistica, es de urgentisima necesidad la fundación del sobredicho convento, para los progresos de la vida espiritual. para que ni se pierdan muchas almas, ni ve verifique en nuestros tiempos lo que refiere de los pasados el R. P. Fr. Juan Bautista en la primera parte de sus Advertencias, folio 12: quejabase entonces un sacerdote de que los indios no eran buenos cristianos, a que respondió un indio $y$ dijo: pongan tanto cuidado los padres en bacer a los indios buenos cristianos, como ponian los ministros de los idolos en enseñarles sus titos y ceremonias, que con la mitad de aquel cuidado seremos los indios, buenos cristianos, pues la ley de Cristo es mejor y por falta de quien la enseñe con paciencia, no la toman los indios.

Palabras por cierto muy dignas de consideración si por falta de quien enseñara no eran los indios buenos cristianos, hoy diremos $y$ nos dicen que por falta de conventos donde entrar, sin dote por su pobreza, no son ni pueden ter los indios baenos misticos adelantando en la virtud, y es la praeba Sr. Juan Diego y su mujer María Luisa, por oir un sermón del V. P. Fr. Toribio Motolinia en loor de la virginidad, como refiere el Br. Luis Lazo de la Vega en su Historia de Nueatra Señora de Guadalape, quedaron tan enamorados de la castidad que de común coneentimiento gozidaron en adelante perpetua castidad y continencia.

En el paeblo de Guaxosingo, el V. P. Fr. Miguel de Estibales, compelido de 13 obediencia de su guardián, que a la sazón lo era de aqquel convento, declaró ante el 
escribano público de aquel lugar, con asistencia de testigas, que en el pueblo de Sinsonsa, ayudándole a la misa con un cirio en la mano a su guardián Fr. Pedro de Reina, vió después de la consagración que se voló una forma del altar $y$ se le fué a meter en la boca a una india que estaba detrás de la puerta de la iglesia oyendo la misa; pues esta bendita india y María Luisa si bubieran tenido por entonces un convento, ¿quién duda que recogidas $y$ doctrinadas en él con doctrina religiosa, hubieran pasado a mayor perfección. y de esto a más crecida santidad, para mayor gloria de Dios?

Ni tampoco señor. podemos negar que el dia de hoy hay entre las indios anos espíritus tan puros y semejantes a los de las referidas: pero éstos no re anmentan y crecen por la falta que hay de recogimiento religioso en convento, pues aunque tengan como tienen el bastante cultivo de padres espirituales se distraen mucho con el comercio del siglo, lo cual no padecieron si lograran la recogida quietud de un convento, porque allí, quitadas de todo el manejo secular se entragaran todo $y$ del todo a solo Dios; y aunque es verdad señor, que bay muchos espiritus tan valientes y agigantados que entre las espinas del siglo no se sofocan sino que entre ellos dan rosas de virtudes y frutos de santidad, también hay otros espíritus tan delicados y melindrosos que el aire del siglo los marchita, y éstos necesitan del retiro y soledad del claus.tro para su conservación y aumento, $y$ más cuando la virginidad $y$ castidad es una virtud tan delicada que siempre se mancha con los corruptos aires de una conversación poco pura, que rara vez falta en el siglo. F más cuanto sin custodia se pretende conservar ilesa, pues las más veces dejan a las doncellas sus padres por guardas de sus casas, solas $y$ sin compañia, de que lloran lastimosamente con la esposa, que puestas por guardas no pudieron guardar la viña de su propia virginidad; esta lástima la lloramos en los confesonarios cada día, pues en 32 años de administrar y de ellos los 26 de cura, e oido mucho de esto $y$ muchos espíritus que podían adelantarse, con muchas creces se han atrasado por la falta de recogimiento.

Señor: no es menos vuestro celo y deseo de que se propague la fe católica que la del Sr. Felipe IV, de gloriosa memoria, a quien representándole que en la isla de Terranate, en Filipinas, se gastaban muchos haberes reales sin utilidad, preguntó $S$. M. : ¿arde la límpara del Santísimo en Terranate? $y$ respondiéndole que sí, dijo como tan católico; como arda la lámpara del Santísimo, gástese todo mi patrimonio; bien sabe V. A. S. que cada alma es ana luz que le alumbra a Dios, y quedarí V. $\mathbf{A}$. con tan grande fé como arde en su real pecho porque le ardan continuamente de día y de noche, encendidos en af fuego de amor, veinte lucientes lámparas en veinte puras esposas que de dia $y$ de noche le asistan al Celestial Esposo Sacramentado, sirviéndole amorosas. Si por una lámpara que arde materialmente se da un patrimonio, por veinte lámparas espirituales que arden en amor de Dios ¿qué dará $V$. A $Y$ tengo cierto, señor, que el proponerle a V. A. la fundación dal convento que se pretende es paladiarle el amoroso e insaciable deseo que $V$. $A$. tiene del logro espiritual de los indios. pues tan encargados los tiene con sus repetidas reales cédalas.

Pues aquién manda en la ley diecinueve, titulo 3 del libro 1 de la Nueva Recopilación, que se procure la conservación de las casas en donde se les enseña a las niñas no sólo la vida espiritual sino la politica, por parecerle a $\mathrm{S}$. M. necesaria dicha conservación, porque es obra piadosa $e$ importante al servicio de Dios $y$ bien de estas provincias? por lo cual manda S. M. que donde no hubiere dichas casas, se funden, $y$ 
fundadas, se conserven, verà muy bien como tan católico que mucho más necesario c importante al servicio de Dios y bien de estas provincias será la fundación del convento de Descalzas para las indias nobles, pues en él se remediarán muchos daños que lloran las provincias por no haber conventos en que se remedien sus vidas, $y$ lo más es que aprovecharán en la carrera de la vida espiritual y austera de una religión con las creces del espititu, lo cual no se puede con facilidad en el siglo porque ni puede florecer ni fructificar con desahogo en donde a cada paso sufran los espíritus la conversación de lo mundano: $y$ asi, señor, me parece que $V$. A. quiso obligarse con la referida ley a la fundación del sobredicho convento, porque si $S$. M., que Dios guarde, manda que se erijan, fuaden y se conserven las casas en donde se les enseñe la vida espiritual y política, en donde se les podrá, señor, instruír en vida política y virtuosa si no en nn convento en donde todo es política religiosa: y si aquella casa es necesaria, la fundación de este convento la juzgo por necesarisima a todas las provincias, pues dándose entrada a las más perfectas para estado religioso en dicho convento, con emulación espiritual, tratarán las que quedan en el siglo, de ascender a mayor perfección por lograr la dicba de consagrarse a Dios en espiritual matrimonio con $S$. M.; Y si una dragma perdida fué causa de grandes regocijos entre los vecinos que dice San Mateo, y un convertido pecador aumentó la gloria occidental a los ángeles del cielo, ¿qué regocigos y gloria se le dara a Dios con muchas joyas y dragmas en un convento, y muchas almas recogidas para el servicio de Dios en un clanstro? por esta gloria que estoy cierto que se te ha de seguir a Dios, soy de parecer el que se funde el convento de Descalzas para las indias nobies. Salve, etc. De vuestra parroquia de San José, 10 de mayo de 1723.

M. P. S.

Besa los pies de V. A, su rendido y menor capellán y siervo.

Fr. Ignacio García de Figuecoa,

Cara Ministro.- (Rúbrica).

Otrosí: I que si algún inconveniente pudiera tener la fundación del sobrediche convento, pudiera ser la imposibilidad del sustento; pero esto no es óbice ni inconveniente para la ciudad de México, donde son los ánimos tan liberales y la piedad tan nativa. como todo el mundo lo experimenta, pues no contentos con mantener innumerables cofradias $\mathrm{y}$ hermandades sin otras muchas limosnas con que socotre a los de sus límites, y sirven vecinos que sustentan ampliamente a los foráneos, como lo publican muchos conventos de religiosos de la Europa, y quien no se cansa en extender las manos de su piedad a los de afuera, cierto es que tendrá a mucho gusto y se gloriará de darles el sustento a las dichas religiosas, como se tiene por feliz en sustentar a las religíosas capuehinas de esta ciudad, y así respecto del sustento no hay que dudar porque ciudad de tanta piedad puede decir con verdad que descie su infancia nació con ella su misericordia,

$$
\begin{aligned}
& \text { Fr. Ignacio Garcia de Figueroa, } \\
& \text { Cara Ministro.-- (Rúbrica). }
\end{aligned}
$$

1 Historia. Tomo 109. Fs. 7 a 8. 


\section{PARECER DEL P. ALEJANDRO ROMANO}

Muy poderoso señor:

Me mandó V. A. por auto de vuestro Real Acuerdo, que expresase mi parecer en orden a una fundación de religiosas caciques que se intenta en esta imperial ciudad de México, y obedeciendo como debo a cste mandato digo que no hallo disposición en las indias, antes si positiva ineptitud para ser religiosas. por las razones siguientes:

Son las religiosas unas señoras cristianas que deseando conseguir la perfección de todas las virtudes, profesan de vivir en comunidad y en perpetua clausura debajo de la obediencia de una prelada que las obligue a guardar los tres votos comunes a todos los religiosos y otras reglas $y$ estatutos que se juzgan ser medios eficaces para conseguir su fin; para nada de todo esto yo veo disposición en las indias.

Primeramente no tienen natural para poder vivir en comunidad, como lo manificsta su modo antiguo y presente de vivir, pues antes de la venida de nuestra santa fe a estas tierras (quitados los que vivían en compañia de sus reyezuelos) los demás moraban en los montes y en rancherias pequeñas, como aún acostumbran los gentiles, los cuales aunque después del Santo Bautismo, a costa de mucho trabajo de sus ministros se hayan reducido y se vayan reduciendo a pueblos, siempre han conservado $y$ conscrvan en gran parte su natural oposición a la vida sociable y civil, pues cada uno fabrica su casa bien distante de la del otro, lo cual puede nacer de una de estas dos tazones: o porque no tienen paciencia $y$ prudencia para sufrir y disimular alguna molestia del vecino o para que no sean notadas sus acciones. o por to uno $y$ por lo otro, que es lo más verosímil; y si el natural de los indios es tal que no puede sufrir el vivir inmediato a otro, ¿cómo podrán acostumbrarse las indias a vivir juntas en una casa, expuesta cada una a la vista de todas que le noten sus acciones para que se las corrija su prelada, $y$ obligada a disimular $y$ a sufrir las molestias de todas?

Falta también, generalmente bablando de todos los indios, la constancia del ánimo en sus buenos propósitos, como nos enseña la experiencia, y aunque ésta faltara, nos lo hiciera manifiesta la razón porque la facilidad en mudar de parecer $y$ de voluntad se origina, como enseñó Santo Tomás, de la imperfeceión del entendimiento en conocer los objetos; por esta razón los ángeles que clara y perfectamente conocen las cosas, son muy tenaces en sus juicios y afectos, y por la misma razón vemos en los hombres que los más cortos de entendimiento son también más expuestos a mudar de parecer y de voluntad. Siendo pues notoria la suma cortedad de entendimiento en los indios, a la cual se sigue como su propiedad la inconstancia quien no ve la ineptitud que tienen las caciques para el estado religioso, el cual dice perpetuidad en el ejercicio de virtudes muy arduas y repugnantes a la humana naturaleza.

Confirma este discurso la experiencia porque no hay duda que es más fácil $y$ menos repugnante a la bnmana flaqueza el cumplir con las obligaciones de casado que $\operatorname{con}$ las de religioso, y con todo apenas se hallará india casada que no se haya atrepentido de serlo, y muchas de ellas se arrepienten tan deveras que dejan para siempre a sus maridos, por lo cual yo no veo cómo pueda dictar la prudencia que mujeres tan inconstantes profesen estado de religión y de clausura perpetua. el cual piđe mucha constancia de ánimo y no menos fortaleza, que falta también generalmente en las in- 
dias. pot cuya causa son ineptas para el cstado religioso, pues éste es estado de mottificación de todas las pasiones y de un continuo anhelo a la abregación de la propia voluntad, lo cual no se puede conseguir sin una sran fortaicza de ánirno, cfecto co gran parte del entendimicnto que dzccubre a la voingtad lo honesto de las virtudes escondidas a los sentidos, $y$ con eso la alienta $y$ esfuerza a mortificar sus apetitos desordenados. For esta razón todos los padres y directores de espíritn encargan tanto la reditación de las verdades eternas a los que tienen a su cuidado, porque sin ésta no puede haber fortaleza en el almar sin fortaleza no puede baber mortifieación y sin mortificación es locura el pretender ajcanzar virtud alguna. Siendo pues notorio, que el entendimicnto de las indias es cortisimo, es tambión manifiesto que son incapaees para bien meditar de sí mismas las verdjies etzrnas, y consiguientemente, que les falta la fortaleza de animo tan necesario pna mortificar las pasiones $y$ para llevar no sciamente la eruz que el Señor manda cargar a todos los cristianos como medio necesario para aicanzar el cielo, mos también la mós pesada y más difícil para llevarse. y por cso no quiso que fuese obligatoria sino de consejo, cual es la de los religiosos que poe mís agradar á Secior prometen con voto varias cosas muy arduas y dificiles de ejecutarse. Que las indias sean de entendimiento tan corto que no puedan meditar y discuzirir seriamente sobre las verdades de nuestra fe me lo ha enseñado la experiencia de treinta años que las manejo, pues por diligencias que he becho para enseñarles el modo de meditar, todis han salido vanas y sin fruto.

Dudan los doctores si sea válido o no at roto de eastidad que hace quien es sumamente inclinado a la incontinencia, y muchos de cllos y muy graves afirman que no. fundados en que este voto respectivo a tal persona non est de meliori bono. ni puede set sacrificio agradabte al Señor por faltarle la sal de la prudencia. Yo no quiero que estas razones valgan para probar en las indias la incapacidad de ser reji. giosas, por la suma dificultad que han de hallar en eumplir con todas las obligaciones de este estado; pero ¿quién podrá negarme que dichas razones a lo menos convencẹn que no se les debe permitir el que profesen estado, que les puede ser oeasión más de tropiezo que de provecho espiritual?

$\mathrm{Ni}$ a esto se satisface con decir que la gracia divina y no la luz de nuestro discurso es la que enfrena y sujeta nuestras pasiones, potque la gracia no solamente obra en nosotros, más también con nosotros, y ordinariamente se acomoda a la naturaleza como nos enscñan los doctores. los cuales también afirman que de los talentos naturales que el Señor ha dado a alguna persona se puede colegir el empleo a que la destina en su iglesia. Constándonos pues ei corto alcance de las indias para conocer to honesto de las virtudes propias de las personas religiosas, no debemos esperar que el $\mathrm{Se}$ ñor supla su falta natural con luz extraordinaria, sino juzgar que no las quiere para tal estado, supuesto que las negó el talento del entendimiento y discurso tan necesario, según el orden de su providencia ordinatia, para alcanzar las virtudes religiosas.

Pero sobre todo yo no veo en las indias ni rastro tampoco de aquella gran prudencia y cordura que se requiere en una superiora para gobernar a una comuridad de mujeres incapaces, y en la súbdita para obedecer a una prelada de la misma calidad, porque pata bien gobernar a gente incapaz se necesita en quien gobierna de gran conocimiento de las inelinaciones $\mathbf{y}$ disposiciones del ánimo de cada ana de sas súbditas, como también de mucho disimulo, paciencia y destreza, llevando a cada nna por su 
camino y sufriéndole muchas faltas, sin perjuicio empero de bien común. cualidades que no se pueden esperar sino casi milagrosamente en una superiora india de poquísimo alcance, $y$ menos se puede esperar en las subditas, inçapaces a aquella beroica humildad, paciencia y obediencia ciega que se requiere para sufrir a una superiora ignotante $y$ consiguientemente indiscreta.

Esto pues, mny poderoso señor, es mi parecer en orden a la nueva fundacion que se intenta, y creo que de este mismo parecer han sido y son cuantos superiores de religiones ha habido hasta ahora $y$ bay en este inmenso teino, porque siendo los indios capaces de ser religiosos, siendo también naturalmente tan humildes. con todo ningún superior los ha querido ni los quicre admitir aun por legos en sa religión, por ser mucha su incapacidad, inconstançia y flaqueza de ánimo, razones que deben tener más fuerza hablando de las indias, por set de sexo más imperfecto.

También juzgo que este parecer es conforme al juicio que de esta gente han hecho los supremos gobernadores de ella. así eclesiásticos como seglares, porque aquélios, considerando so gran flaqueza en vencer sus pasiones nacida en gran parte de su poco alcance. los han eximido de la obligación de guardar algunas leyes eclesiásticas que obligan a todos los eristianos, y éstos por la misma tazón considerándolos como a pupilos y menotes, dan por nulos sus contratos hechos, sin consentimiento de quien está en Iugar de su tutor. México y mayo veinte de mil satecientos y veintitrés.

$$
\text { Alejandro Romano.- (Rúbrica). }
$$

(Ramo de Historia. Tomo 109. Fs, 19 rto. a 22 tto.)

Real acuerdo de México y noviembre 4 de 1723 años. Stes. S. E. Marqués de Villa Hermosa de Alfaro, Oliván, Gutiérrez Picado, presente el señor oidor fiscal.

Hágase informe a $S$. M. de ser conveniente la nueva fundación de religiosas de San Francisco. indias caciques por parecer ser de servicio de Dios y de $S$. M. para lo cual y lo acordado pasen estos autos al señor oidor D. Juan de Olivàn Revolledo a quien S. E. ba nombrado para este efecto.

$$
\text { (Una rúbrica). }
$$

Real acuerdo de México y junio 26 de 1724 años.

Al señor fiscal.

(Una rúbrica).

Muy poderoso señor:

El Dr. D. Matias Navarto, presbítero rector del Colegio Real de Cristo de esta ciudad en nombre del E. S. Marqués de Valero, Gentilhombres de la Cámarz de S. M. Mayordomo Mayor con futura de la reina nuestra señora, presidente en propiedad del Real y Supreno Consejo de las Indias y de la junta de estado de las naciones extrajjeras $y$ uno de los ministros que componen el real gabinete, como mejor en dezecho proceda, digo que babiendo deseado el fervoroso celo de dicho $\mathbf{S}$. $E$. mien- 
rras ejerció los cargos de vaestro Virrey de este reino, emplearse en alguna obra de piedad que principalmente se dice en beneficio $y$ consuelo de los naturales, se persuadió firmemente a que ningún medio sería más oportuno para el logro de tan recomendado fin que la construcción de un monasterio en que pudiesen profesat el estado religioso las indias principales e bijas de caciques que tuviesen vocación a el, y habiendo comunicado su noble pensamiento a vuestro Reverendo Arzobispo de este ar" zobispado no sćlo le aprobó manifestando cristiana emulación que le quedaba de que se le bubiese prevenido ea él sino que dió su licencia y permiso para que redujese a efecto a que también asintió el Cabildo Secular de esta nobilísima ciudad con cuyos miembros sé dió principio a la construcción y fábrica, habiendo concurrido a la sagrada ceremonia de afijar la cruz y poner la primera piedra los prelados de las religiones que tenian interés $y$ podian ser perjudicados en ella, y habiéndose acabado $y$ aplicado las demás disposiciones previas $y$ respectivas al culto divino $y$ régimen espiritual de las religiosas no restaba otra cosa para la práctica que el que viniese la licencia de vuestro reverendo padre que estaba impetrada y habiéndose dignado de concederla la presentó ante $V$. A. con el juramento y solemnidad necesaria para que en su vista se sirva darla el paso, mandando se guarde, cumpla y ejecute todo lo que Vuestro Reverendo Padre previene y ordena en ella y que quedando copiada en los libros se me devuclva original para los efectos que convenga.

A V. E. suplico que habiendo por presentada dicha real licencia se sitva mandar bacer como pido con justicia juro en forma y en lo necesario, $\mathbb{S}$.

$$
\text { Dr. Matías Navarro.- (Rúbrica). }
$$

En 26 de junio de 724.

Muy poderoso señot:

Nuestro fiscal en vista de este escrito $y$ de la teal licencia que con él se presenta expedida en favor del Excmo. St. Marqués de Valeto, para fundar en esta ciudad un convento de religiosas Franciscas Descalzas para indias principales e hijas de caciques. conforme a las reglas del real patronato, cuyo paso se solicica.-Dice que una de las reglas más conocidas en esta materia es el que el propio específico y verdadero derecho de patronato (distinto del genćrico $y$ absoluto que compete a vuestra real persona como rey y señor soberano y le atribuye la misión y defensa de las comunidades eclesiásticas y religiosas que residen dentro de sus dominios) sólo se adquíere por ta construcción, dotación o concesión del suelo, la cual procede no sólo en los patronatos particula res, sino también el real en que es preciso concurran las tres causas referidas o alguna de ellas para que vaestra real persona pueda tenerle y usar de la regalia y fruco civil que le corresponde $y$ no habiéndose vetificado en la fundación de que se trata ninguno de los requisitos mencionados por haberse hecho toda a expensas de dicho Excmo. Sr. Marqués de Valero, entra sin dificultad lo dispuesto por la ley 23 , título 6 , libro I de la Recopilación de estos Reinos en que se ordena que cuando alguna persona quisiera fundar de su propia bacienda algín monasterio precisa la licencia de vuestra real persona en lo que fuere necesaria se cumpla su voluntad $y$ tenga el patronazgo en él $y$ las demás personas a quien nombrare y llamare y para ocurrir al inconveniente de que 
vuestros presidentes o audiencias se entrometiesen a usat del patronato real en semejantes fundaciones hechas a expensas de particulares se expidió real cédula en nueve de septiembre del año pasado de mil quinientos noventa y cinco que refiere $D$. Pedro Fraso (De Reg. Patronato de Indias. Tomo 1, capítulo 2, n.-25), en cuyos términos y teniendo entendido vuestro fiscal que las disposiciones que dejó hechas dicho Excmo St. Marqués para la fundación de dicho convento son conformes a lo dispuesto por la citada ley de ninguna manera ofensivas al real patronato es de justicia el que $V$. A. se sirva de conceder el paso de la real facultad y licencia que se ba presentado y que quedando copia en los libros se devuelva original a la parte, la cual pide vuestro fiscal. México y junio 27 de 1724.

$$
\text { Lic, Palacios.--(Rúbríca). }
$$

Real Acuerdo de México y julio 3 de 1724 años.

Como lo dice el señor fiscal.

(Una rúbrica).

Sr. Marqués de Villa Hermosa de Oliván. Gutiérrez. Carrillo, Picado, Malo.

En 2 de julio de 1724 se me entregó y devolvió la teal cédula original que presenté en el real acuerdo con el caso dado en cuatro fojas. $y$ para que conste lo firmé dicho día.

$$
\text { Dr. Matías Navarro.-(Rúbrica). }
$$

Suplica se lea.

Muy poderoso señor:

(Una rúbrica).

El Dr. D. Matías Navarro, presbítero tector del Colegio Real de Cristo de esta ciudad en nombre del Excmo. Sr. Marqués de Valero. Gentilhombte de la Cámara de S. M. y Presidente del Real y Snpremo Consejo de Indias, como mejor haya lugar. digo: que $V$. A. ae ha de servir de mandar ae me dé testimonio autorizado en pública forma y manera que haga fé del escrito con que presenté la real ticencia de V. R. P. para la fundación dê sonvento de religiosas Franciscas Descalzas para indias cariques. decretos a él proveídos, respuesta fiscal, $y$ alto en que $V$. $A$. fué servido de mandar se guardase, cumpliese y ejecutase lo que V. R. P. ordena.

A. V. A. suplico se sirva mandar hacer como pido con justicia 8 .

$$
\text { Dr. Matias Navarro.-(Rúbrica). }
$$

(En 14 de Agosto de 1724 se dió el testimonio y entregó al Sr. D. Matias Navarto). 
Los dos estudios que se publican a continuación fueron enviados por sus autores como una cooperación del Instituto de Investigaciones Estéticas de la Universidad Nacional para su presentación en la interesante Asamblea del Instituto Panamericano de Geografía e Historia, celebrada en marzo del presente año en la ciudad de Lima. 